\title{
estructuras laminares cerámicas
}

ํํำ

ㅇำ

Ha sido siempre objeto de singular atención, por parte de arquitectos e ingenieros, el estudio de los problemas que plantea la construcción de cubiertas de grandes luces, y más en estos tiempos que corremos en que todo tiende a superarse.

Siempre me ha interesado el modo de cubrir grandes superficies, sin empleo, naturalmente, de apoyos interiores. Puede decirse que soy un especialista en esta materia, porque, como verán, mi primera cubierta original data de hace treinta y tres años, que corresponde a la del IV Depósito de Aguas de Oviedo. Ahora bien, a diferencia de Torroja y Salvadori, llevo treinta y tres años proyectando y construyendo cubiertas, pero ninguno he dedicado a profundizar en la teoría de las cubiertas laminares, porque no tengo la tas, pero ninguno he dedicado a profundizar en la

응

5
0
0
5
0
0
5
0
0
0
0
0
0
0
0

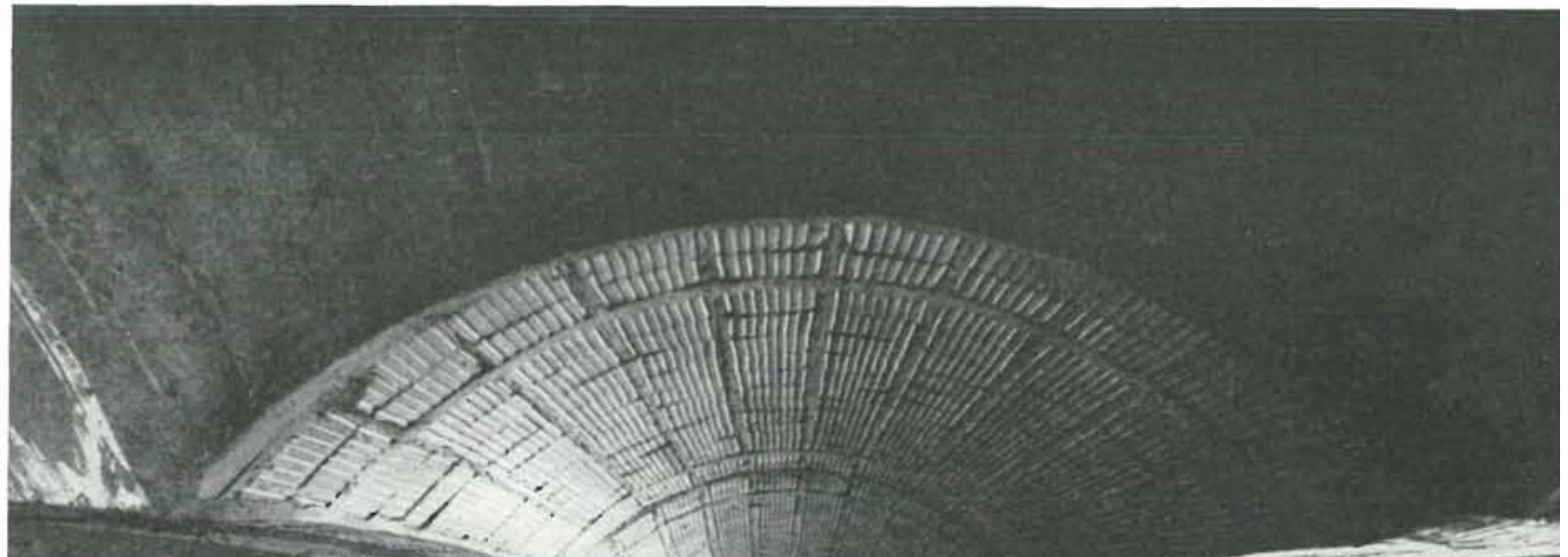

క

is

है

은

$\frac{1}{0}$

동

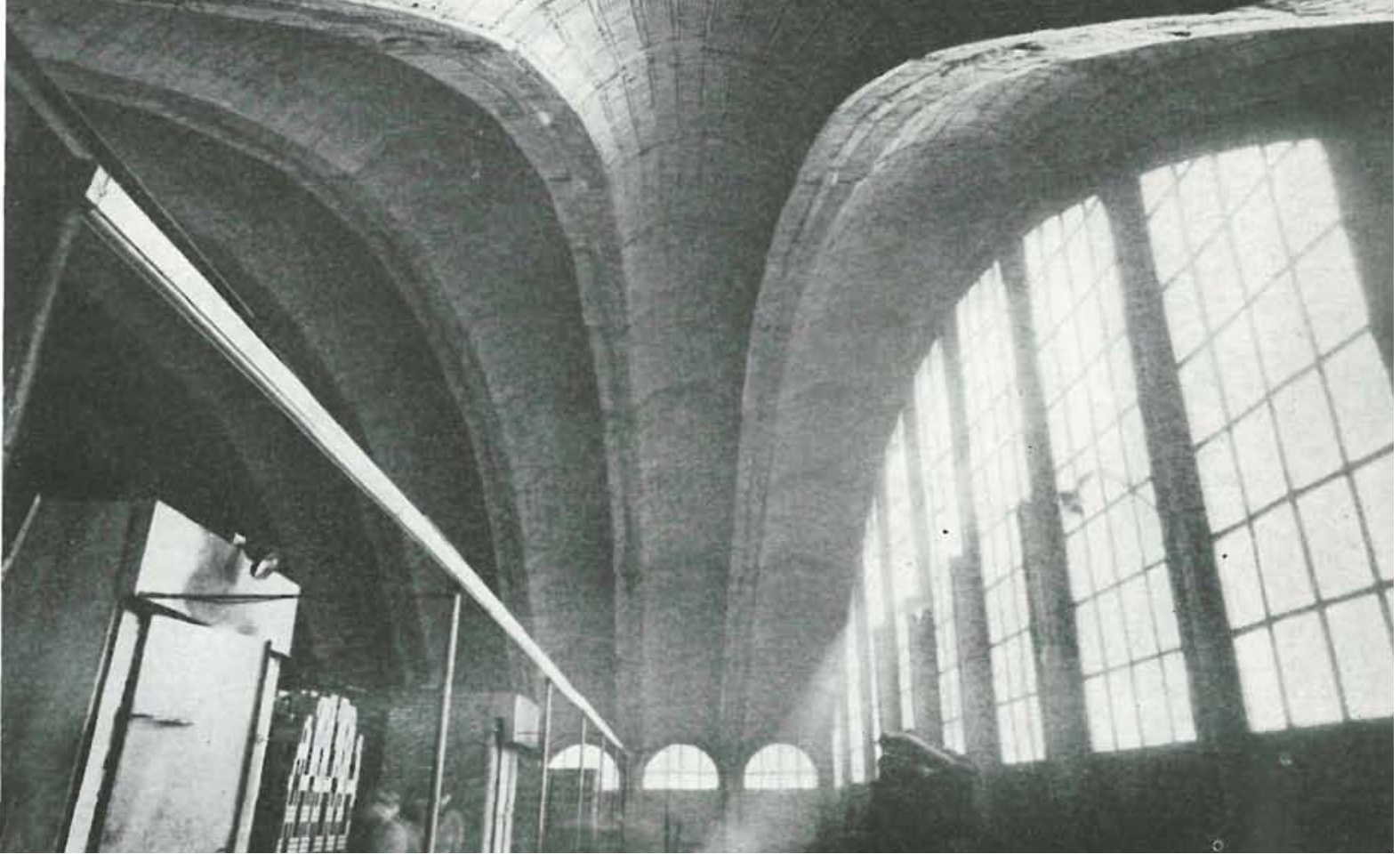


La consecuencia lógica inmediata ha sido la de no proyectar esa clase de cubiertas... Y mis defensas fueron y son, precisamente, esas formas que tanta infuencia tienen en el acierto de soluciones racionales y bellas y que a mí me han liberado de ser esclavo de un cálculo laboriosísimo o imposible.

Es indudable que todo proyectista, desde el momento que se sienta delante del tablero, busca "una forma", porque sabe perfectamente que de su acierto depende el éxito de la obra. Ahora bien, no olvidemos que esa forma es la resultante o suma de otras disposiciones estructurales que, a su vez, hay que buscarles "su forma" lógica y racional en las que por encima de todo debe predominar el buen sentido. Es decir, que un arquitecto-artista debe sacrificar un poco su arte para que la obra sea constructiva $\mathrm{y}$, como consecuencia, económica. $\mathrm{Y}$ un ingeniero-matemático debe procurar no ser esclavo de su ciencia, que muchas veces puede impedirle ver con claridad un amplio horizonte y hacerle incurrir en los mismos fallos que al arquitecto.

Se suele decir: "una obra bien calculada es arquitectónica". Esto es cierto a veces. Pues lo primero que hay que saber es dónde el proyectistamatemático "ha metido" sus cálculos, porque, como dijo muy bien Salvadori, puede suceder que los haya malgastado para obtener como resultante una bóveda "laminar" de ii60 cm de espesor!! o en otras estructuras donde el alquiler de cerebros de verdad o electrónicos no compense el mantener por amor propio una idea; actitud funesta, ya que puede estar abiertamente en pugna con el buen sentido constructivo que debe presidir en todo momento.

He dicho que el acertar con la forma de una estructura aporta al proyectista ventajas de todos los órdenes. Una veces se acierta y otras no. Yo creo que he acertado en algunas, que son las que voy a mostraros... ¡Claro está!

Por tanto, muy brevemente recordaré dos que considero como mis pequeñas viejas glorias, las cuales con toda elocuencia muestran las ventajas que tiene el acertar con la forma, y que, a pesar del tiempo transcurrido, han seguido influenciándome en la solución de algunas disposiciones de mis más recientes obras.

Se trata: del IV Depósito de Aguas de Oviedo, proyectado en 1926, y el Mercado de Pola de Siero, en 1929. La primera crea un sistema constructivo de aplicación normal que se sigue empleando en España. En cuanto al Mercado de Pola de Siero crea también un sistema constructivo, pero de aplicación excepcional, por cuanto se refiere a la cubierta de una superficie triangular (triángulo rectángulo isósceles).

El examen de la figura 1 del Depósito de Aguas de Oviedo hace ver inmediatamente, en qué se basa su procedimiento constructivo. El recinto del agua es tórico, integrado por un cilindro central resistente, aprovechado su interior para.emplazar la cámara de llaves. Su parte superior lo constituye el anillo resistente, de donde arrancan los 48 nervios radiales de la cubierta que se apoyan en el otro extremo en sendos contrafuertes de mampostería. El anillo central trabaja, por tanto, en condiciones óptimas de compresión simple. En cuanto a los nervios, se les da una sección ancha para que ellos contribuyan a cubrir la superficie del depósito, de modo que la suma de sus anchos es el perímetro exterior del anillo resistente (fig. 2). Los paños triangulares que

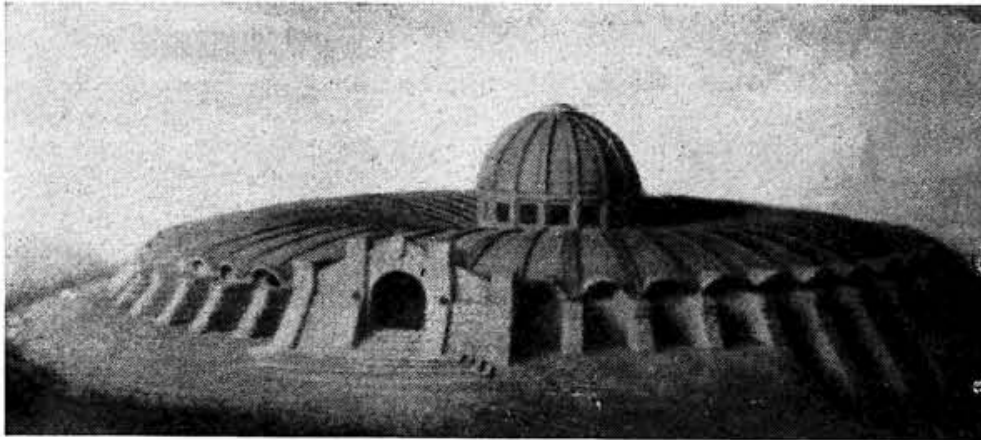

1

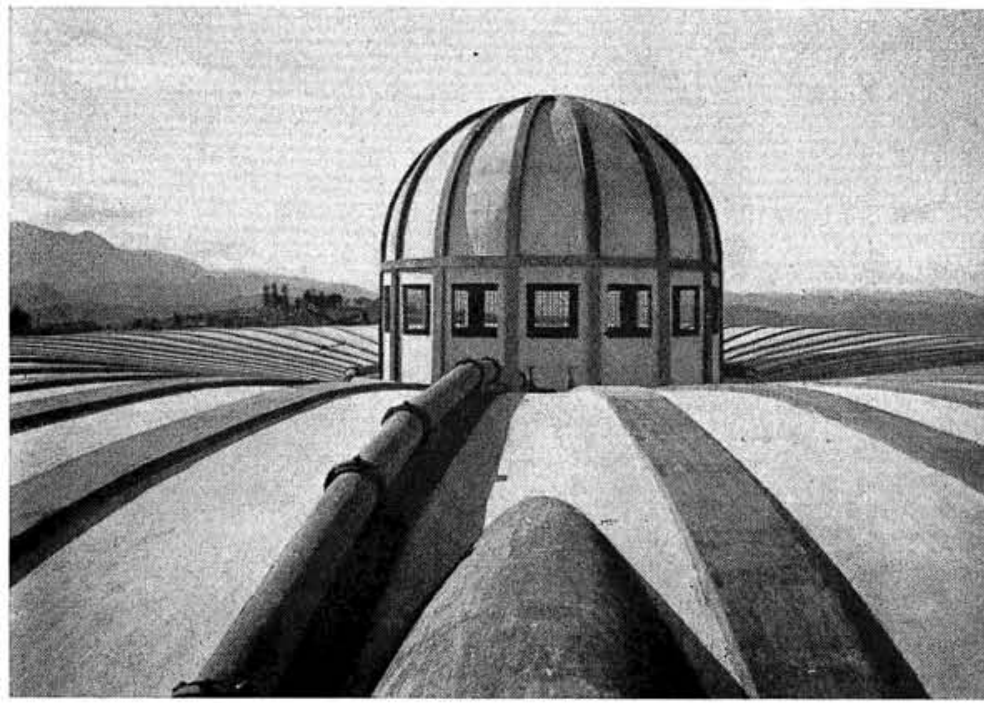

2

3

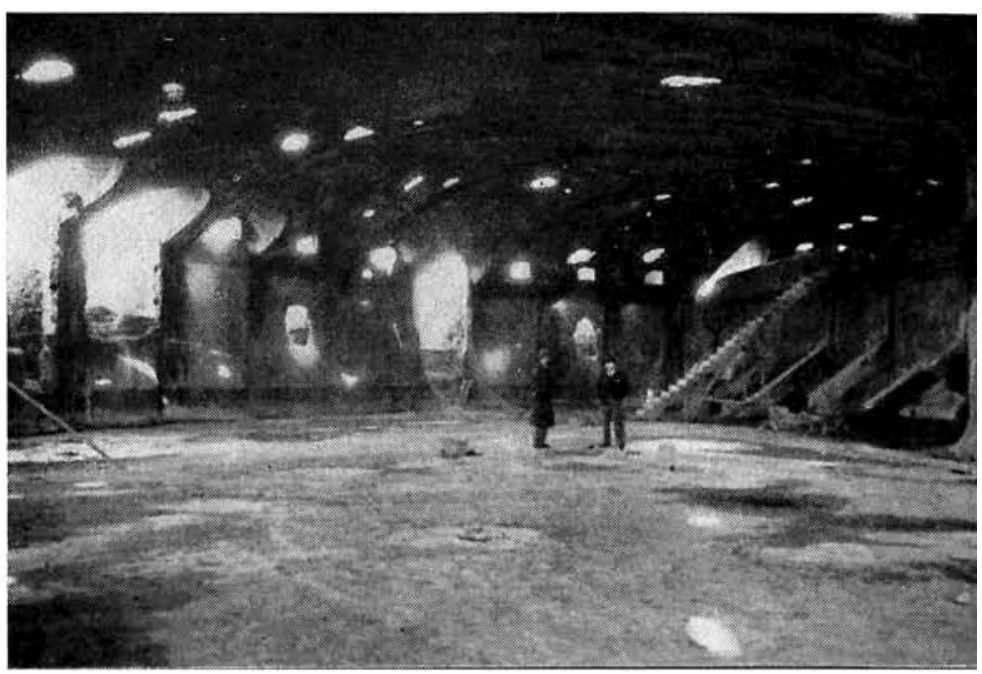


quedan libres entre los nervios se tapan con un forjado de hormigón armado. La pared cilíndrica del vaso del depósito está integrada por los contrafuertes y por unas pantallas circulares invertidas apoyadas en ellos. Estas pantallas, por el empuje del agua, pueden considerarse que trabajan a compresión simple.

Fácilmente se comprende que concebida así "la forma", todo ha resultado fácil. Su cálculo es elemental; a los nervios se les dió la figura antifunicular de la carga triangulada que soportan, es decir, una parábola cúbica. Es la única integral inmediata que hubo que efectuar, la cual se pudo evitar obteniendo dicha parábola gráficamente.

Si fácil fué el cálculo, tan fácil fué su construcción mediante dos sectores opuestos de cimbra giratoria alrededor de la cámara de llaves.

Puse especial atención en que el conjunto de esta obra original fuese agradable y armonioso. Así, salieron las soluciones de detalles: puerta de entrada, cúpula y las graciosas viseras que rematan los contrafuertes y contornean la cubierta del depósito. Son además funcionales, porque impiden que el sol penetre en el depósito por los pequeños ventanales abiertos en la parte superior de las pantallas circulares. Ruego no olviden estas simpáticas viseras, ya que las verán como solución casi obligada en los arranques de las bóvedas onduladas.

Esta obra, de aspecto guerrero, el azar la convirtió en auténtico fuerte durante nuestra guerra civil en 1936. Pero su admirable estabilidad no peligró, a pesar de los bombardeos que soportó de los dos bandos beligerantes (fig. 3). $\mathrm{Y}$ es indudable que el éxito completo se debió única y exclusivamente a "su forma", excepcionalmente constructiva y racional. La superficie tórica pudo haberse resuelto con una lámina; pero, ipara qué complicar la cosa, a sabiendas que no se iba a tener ninguna ventaja de ejecución ni económica!

La segunda cubierta que quiero brevemente recordar, antes de pasar al tema principal, es la del Mercado de Pola de Siero, puesto que es de un indudable interés constructivo, debido a sus dimensiones y su planta en triángulo rectángulo isósceles (figuras 4,5 y 6 ).

Construída en 1930, y dada a conocer en diversas revistas técnicas nacionales y extranjeras de la época, la recuerdo siempre con cariño, porque, debido a "su forma", pude liberarme de unos cálculos que se presentían de gran complicación. Todo quedó resuelto gráficamente mediante polígonos de fuerza, funiculares y diagramas de Mohr para la flexión compuesta y por la posibilidad de poder realizar - debido a su forma-ciertos malabarismos con las fuerzas solicitantes.

La cubierta fué concebida por la intersección de dos superficies cilíndricas parabólicas proyectada en planta, en BO. El encuentro de estas dos superficies cilíndricas con el plano de fachada, AC, produce las dos parábolas, OA y OC. Y si las suponemos constituídas por nervios, tales como los ON, YX, vemos que este último, YX, por ejemplo, produce en el borde, $\mathrm{Y}$, una fuerza, $\mathrm{Y} 1$, que se descompone en la 2 y 3. La 2 está en el plano de fachada y puede fácilmente ser llevada al punto $O, y$ la 3 puede, a su vez, ser llevada por tirantes dentro del forjado colgado de los nervios al punto, $\mathrm{P}$, del arco de intersección de las dos superficies cilíndricas.

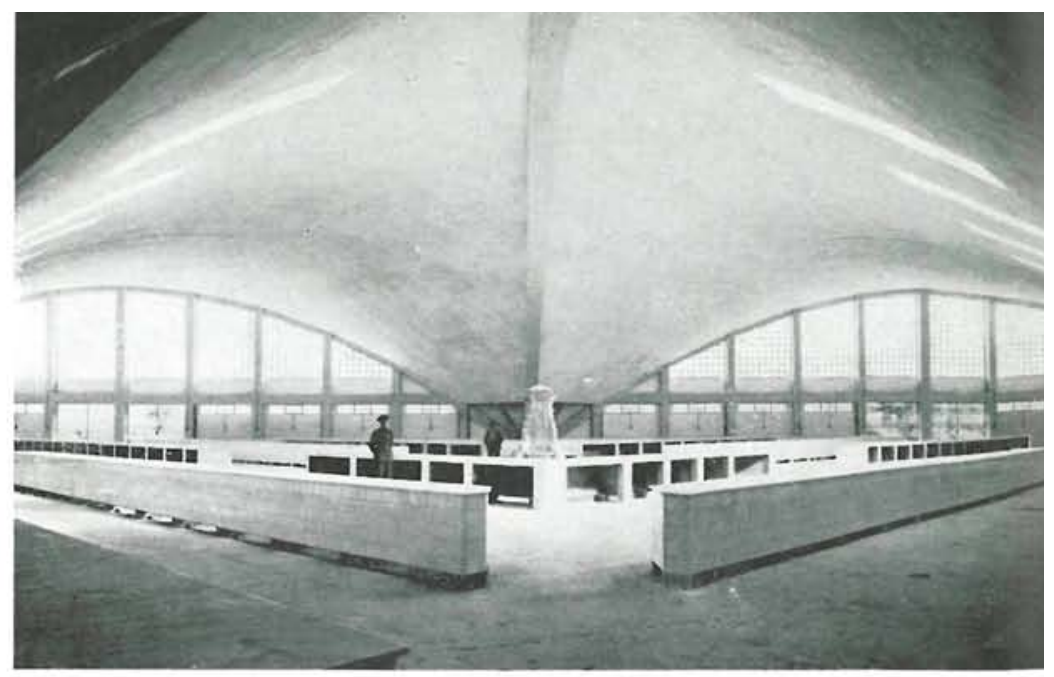

4
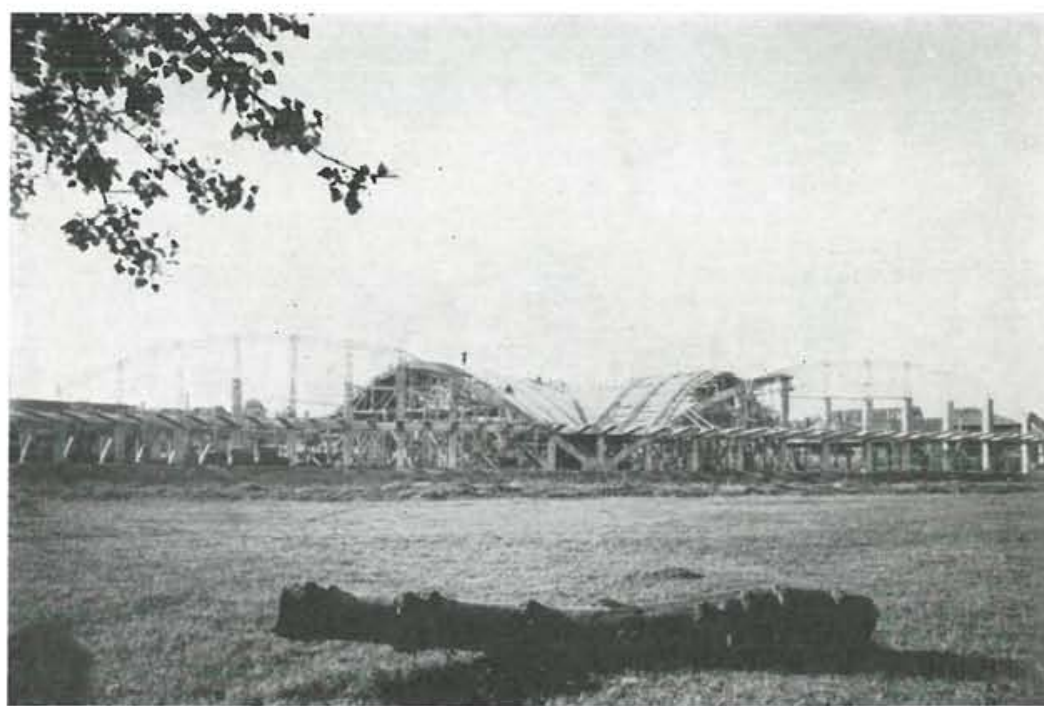

5

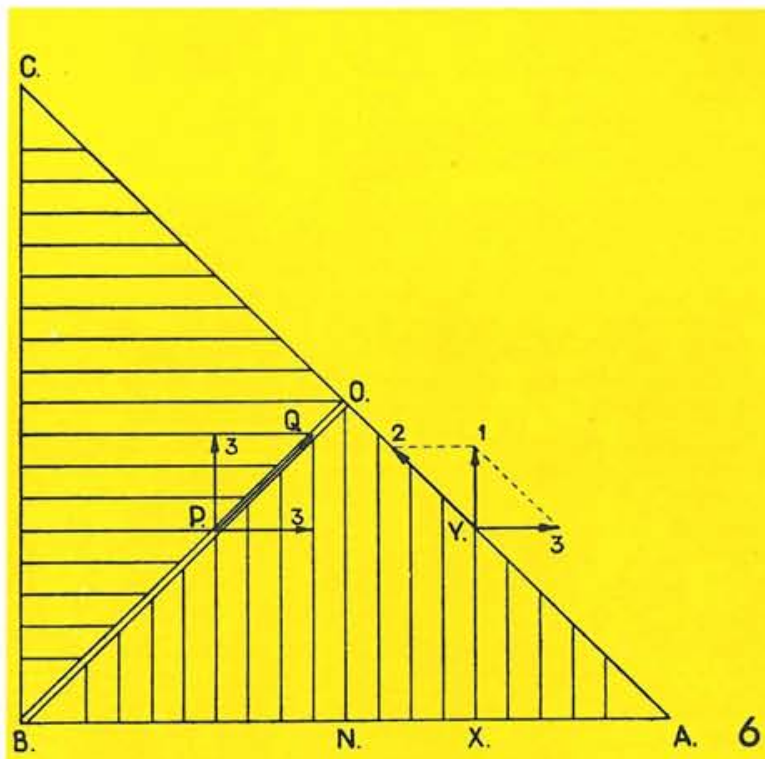




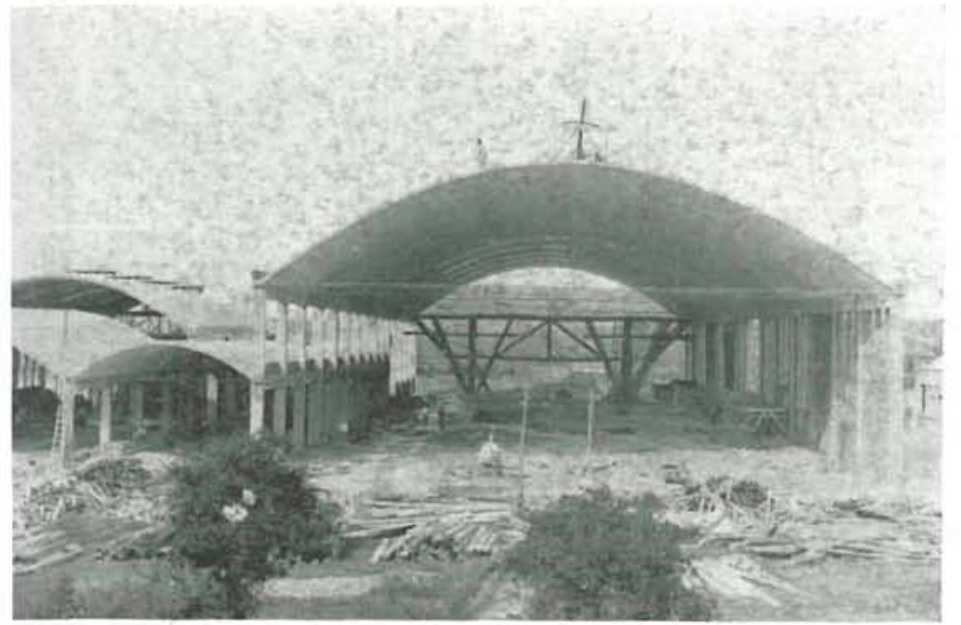

7

Compuesta con la simétrica y los pesos correspondientes, se produce una resultante PQ. Es decir, que existen varias resultantes, $\mathrm{PQ}$, dentro del plano, $\mathrm{BO}$, con inclinaciones diferentes, que pueden ser absorbidas por un arco funicular que las concentra en $\mathrm{O}$, como se ve en la figura 5 .

La construcción de la cubierta se llevó a efecto mediante dos cimbras centrales a las que se iban quitando elementos para permitir su traslación (fig. 6). Siendo $A C=118 \mathrm{~m}$, la superficie cubierta fué de $\mathrm{S}=3.000 \mathrm{~m}^{2}$.

Esta obra es otro ejemplo, de excepcional valor, de la influencia de "la forma" en el éxito constructivo y económico de una construcción, y ha sido, creemos durante varios años, la cubierta en planta triangular de mayor superficie. Recordemos que Esquillán, con su impresionante y admirable realización de París, la multiplicó casi por 7 .

Han visto ustedes que las cubiertas mencionadas son cubiertas nervadas, con nervios visibles exteriormente, y con forjados colgados con el fin de facilitar su construcción, ya que este extremo de "la constructividad" ha sido siempre para mí una obsesión. Por esto, en seguida me di cuenta de las ventajas que podían tener las soluciones a base del empleo de moldes que servian de encofrados, en la construcción de forjados para pisos o cubiertas, porque podían obtenerse, a la vez, varias ventajas: la de facilitar la construcción, disminuir los encofrados, y mejorar las condiciones estéticas de la obra.

Los primeros moldes empleados fueron de cemento, en el año 1930. La mayor parte de los edificios de Oviedo que se reconstruyeron, debido a los incendios producidos por la revolución roja en 1934, lo fueron con mis sistemas en los que los moldes de hormigón (bien fabricados) se tenían en cuenta en el trabajo del forjado. Con ellos proyecté, y se construyeron, bóvedas parabólicas de $25 \mathrm{~m}$ de luz y $0,20 \mathrm{~m}$ de espesor, y grandes forjados de $20 \mathrm{~m}$ de luz. En realidad eran las mismas estructuras nervadas de antes, pero con las ventajas de no verse los nervios y tener una cámara de aire aislante, favorable para evitar condensaciones de humedad. Pronto observé que los moldes cerámicos reunían condiciones más convenientes que los de cemento: Por ser más ligeros y manejarlos el obrero con más agrado y, sobre todo, por su admirable colaboración en el trabajo con el hormigón. La adherencia del cemento con las piezas cerámicas es perfecta $\mathrm{y}$, por lo tanto, la transmisión de esfuerzos a través de ellas es óptima.

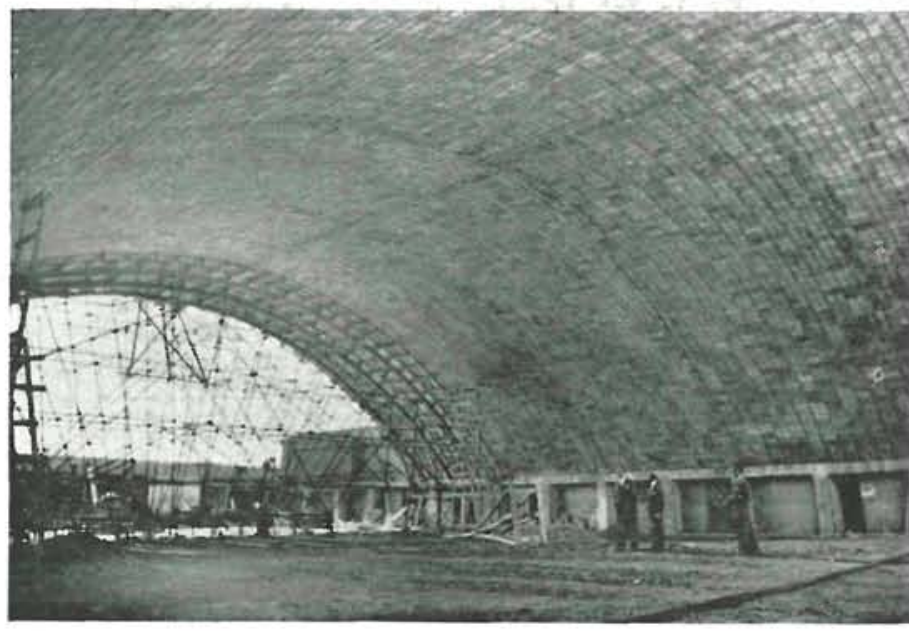

8

APLICABLE BOVEDAS ONDULADAS: $75 \mathrm{~m}$. LUZ

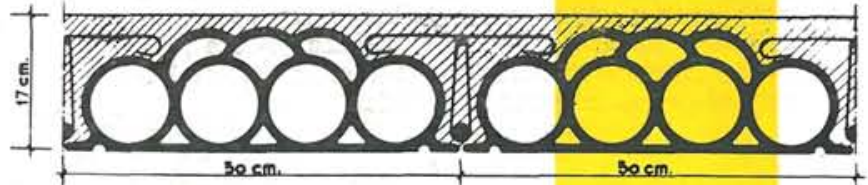

APLICABLE BOVEDAS ONDULADAS:100 m. LUZ

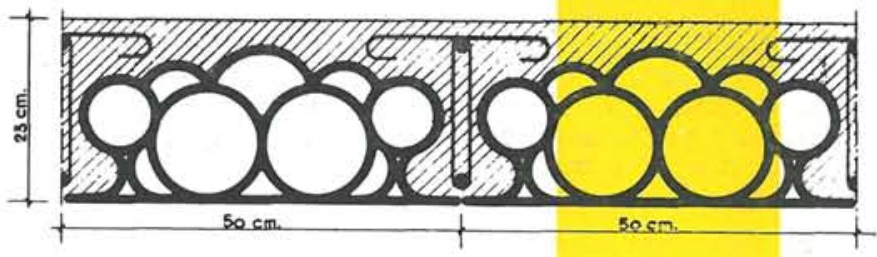

APLICABLE BOVEDAS ONDULADAS: $110 \mathrm{~m}$. LUZ

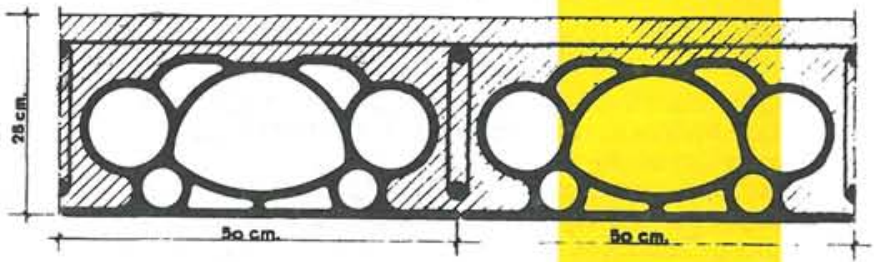

APLICABLE BOVEDAS ONDULADAS: $200 \mathrm{~m}$. LUZ

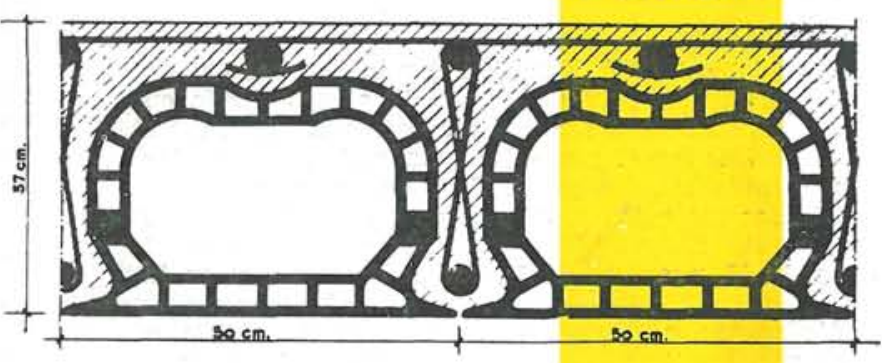

9 
Debido a esto, las cargas tangenciales horizontales de los forjados de pisos y los similares que pueden producirse en las bóvedas son absorbidas en perfectas condiciones, circunstancia que hemos podido comprobar en los muchos af́os de empleo de la cerámica; además, por su avidez de agua y por las grandes superficles de contacto con una masa de hormigón de poco espesor, permite el empleo de mezclas algo más húmedas, lo que facilita el relleno, reduciendo, a la vez, los períodos de fraguado y resistencia. Con toda seguridad, hemos procedido en gran número de ocasiones a desencofrados inferlores a los ocho días. Pero como siempre, "la forma" de los moldes tiene también gran importancia, ya que, dado su tamaño- $50 \times 25 \mathrm{~cm}$ en planta-, deben ser proyectados con miras a facilitar su fabricación, en particular su secado, y para que en la obra produzcan "las formas" de nervadura más convenientes, compatible con un peso mínimo.

Debemos manifestar que la búsqueda de estas "formas" para las piezas cerámicas ha sido laboriosa. Después de contínuados ensayos nos ha llevado a la adopción de formas de piezas un tanto revolucionarias, caracterizadas por su constitución de elementos tubulares que las hacen no solamente muy resistentes y ligeras, sino, a la vez, bellas y manejables (fig. 9), lo que, indudablemente, redunda en su rapidez de colocación. Porque hemos podido comprobar que al obrero le agrada trabajar con estas piezas, lo que conflrma, una vez más, la influencia de la forma, que hay que buscarla no sólo en la primera idea que ha presidido la concepción de la obra, sino en las pequeñas ideas-llamémoslas así-, porque afectan a los más modestos elementos de aquélla.

Pues bien, con forjados nervados curvos, empleando las mencionadas piezas cerámicas de $20 \mathrm{~cm}$ de altura, hemos construído gran variedad de bóvedas hasta $33 \mathrm{~m}$ de luz. La figura 7 corresponde a una bóveda, de esas características, construída para MERSA (Asturias), y la figura 8 pertenece a una nave, de igual luz, para secaderos de Río-Cerámica. La primera es atirantada y la segunda con contrafuertes. La esbeltez de las dos resulta ya impresionante, y se comprende que con tales espesores se esté cerca del límite del pandeo. En efecto, así es, puesto que corresponde a una luz teórica aproximada de $35 \mathrm{~m}$. El peso de estas bóvedas es sensiblemente de unos $210 \mathrm{~kg} / \mathrm{m}^{2}$. Con bóvedas aligeradas con piezas cerámicas de $30 \mathrm{~cm}$ de altura, se pueden salvar luces de $50 \mathrm{~m}$. Es evidente que aumentando los espesores pueden conseguirse mayores luces, pero es a costa de aumentar los pesos y, entonces, la principal característica de este tipo de bóvedas, que es su ligereza, vendrá seriamente afectada, pudiendo quedar en condiciones de inferioridad con relacíón a las clásicas de hormigón armado con nervios de rigidez visibles.

Es decir, que a partir de luces de $30 \mathrm{~m}$ en esta clase de cubiertas aligeradas con moldes cerámicos queda planteada la batalla contra el peso y contra el pandeo. La solución no se hizo esperar.

\section{cubiertas onduladas}

Era preciso recurrir a la solución conocida de ondular las bóvedas, con objeto de alejarnos del pellgro del pandeo y aprovechar todas las ventajas de resistencia que ofrecen las superficies de doble curvatura; pero no hubiera merecido nuestra atención y estudio de no haber tenido la ayuda de otras sugerencias que, aportando nuevas disposiciones constructivas, facilitarán grandemente su aplicación práctica.

Es decir, que en nuestro caso, la idea primaria, conocida de todos, de ondular una bóveda, no se hubiera perseguido $\sin$ la sugerencia de considerarla formada por la yuxtaposición de los "arcos-onda" que, a su vez, podían estar constituídos por unas "dovelas-onda" de características muy especiales y en las que los moldes o piezas cerámicas iban a jugar un papel principal. Han sido, por tanto, un conjunto de ideas, podemos llamarlas de segundo orden, las que han dado "vida constructiva" a la "bóveda ondulada".

El ondular nuestras bóvedas con moldes cerámicos lo expusimos, por primera vez, en el año 1953, en la Universidad de Oviedo, con motivo del Congreso Hispano Lusitano para el Progreso de las Ciencias, confirmado después, en la Universidad de Coimbra, con la exposición de algunas realizaciones $20 \mathrm{~m}$ de luz con espesores de $6.5 \mathrm{~cm}$, de los cuales $5 \mathrm{~cm}$ corresponden a la altura de las piezas cerámicas y $1,5 \mathrm{~cm}$ al recubrimiento de mortero.

La búsqueda de "la forma" más conveniente de la onda, es decir, la generatriz de la bóveda era esencial, pues de ella dependía la del interior de la cubierta, de gran interés bajo el punto de vista de su ejecución por una cimbra con máxima facilidad de traslación, dependiendo también de ella los elementos prefabricados, que deberian ofrecer las máximas facilidades de ejecución.

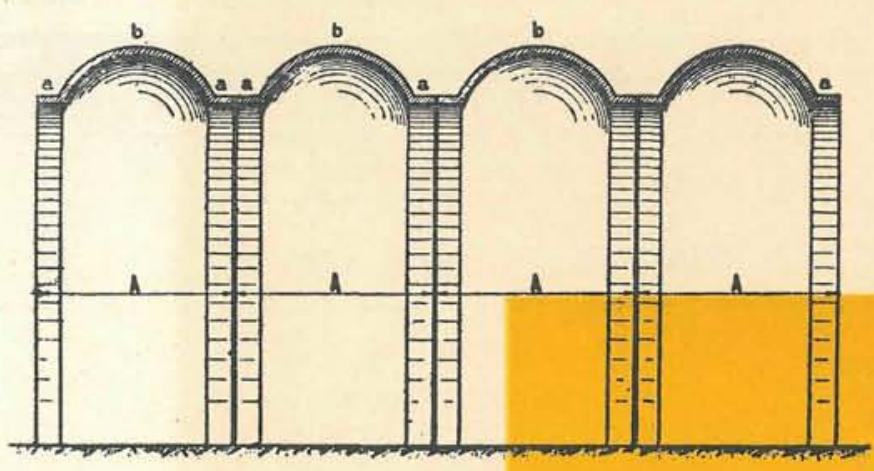

10

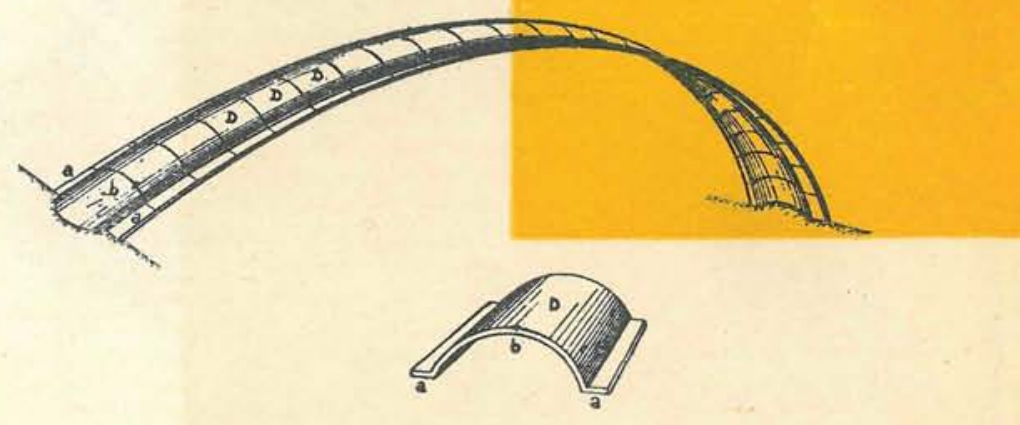




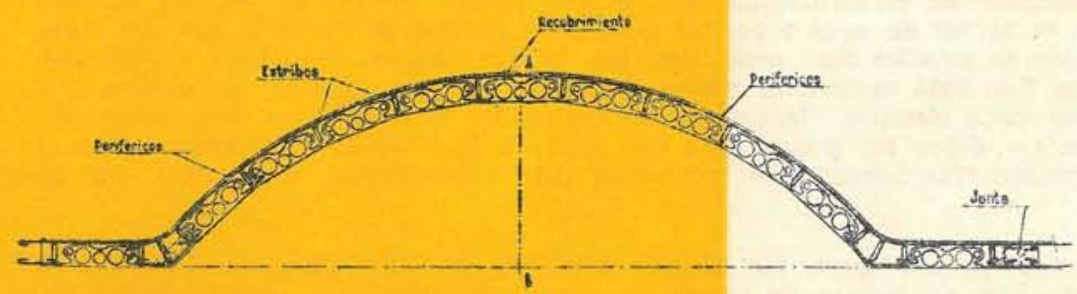

12

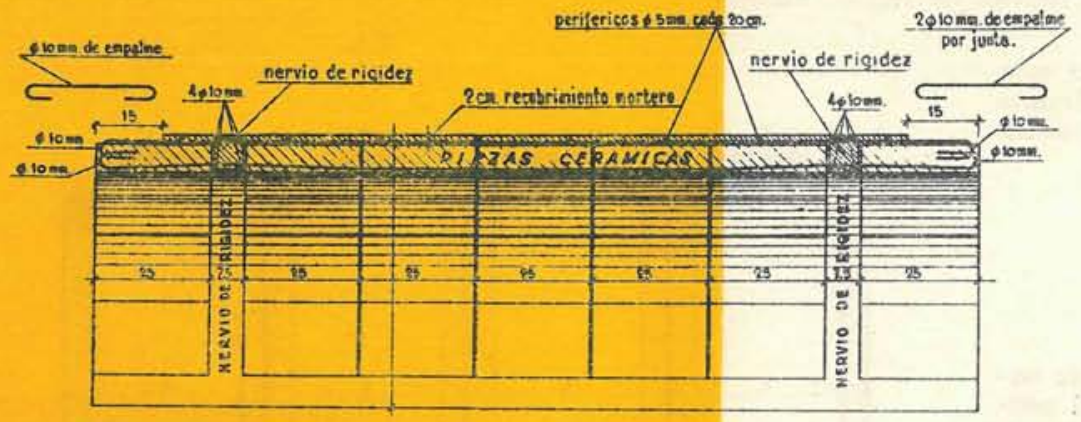

13

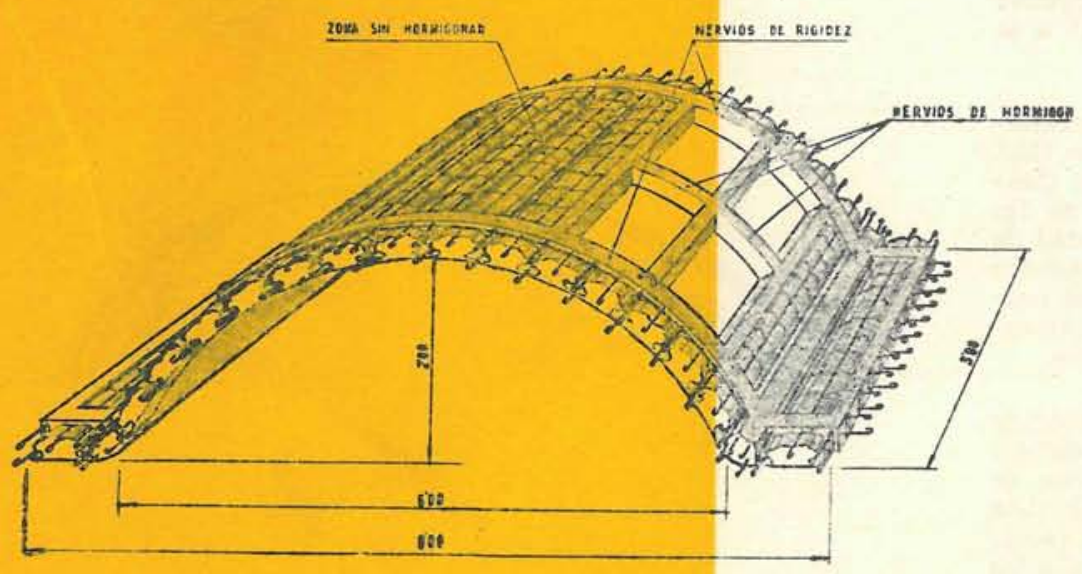

14
Pronto comprobamos que "la forma" de generatriz más racional, que mejor satisfacía las condiciones impuestas, correspondía a la de una onda mixta, compuesta por partes curvas y rectas. Asi, un elemento de esta onda quedaría integrado por un arco de circunferencia y dos aletas rectas, parecido a la "omega" __ . Es indudable que esta directriz por presentar partes rectas serían las que corresponderían a las superficies de apoyo sobre la cimbra, que, como veremos, pueden reducirse a un mínimo, dado que los elementos prefabricados-las "dovelas-onda"-tienen rigidez suficiente para sustentarse sobre cuatro puntos próximos a sus esquinas. Es decir, que dicha rigidez es esencial y a ella contribuye "la forma" lógica elegida para la ondulación.

\section{arcos-onda y dovelas-onda}

Según esto, la sección longitudinal, por la clave de una cubierta de este tipo, sería la de la figura 10, que puede considerarse integrada por la yuxtaposición de los "arcos-onda", A, con estabilidad propia (figura 11). A su vez, si a éstos los suponemos secclonados transversalmente, vemos que pueden estar construídos por las dovelas especiales, D, de igual o variable longitud. A estas dovelas se les llama correctamente "dovelas-onda".

De lo expuesto se desprende que la "dovela-onda" es el elemento base de la construcción de nuestra bóveda ondulada- $y$, por lo tanto, a su ejecución se ha prestado la máxima atención-y que, como veremos más adelante, de ella depende el que puedan conseguirse luces extraordinarias.

Como es natural, hemos mantenido nuestro criterio de emplear en su construcción los tres materiales: hormigón, cerámica y hierro. El correcto acoplamiento de ellos, como se ha visto, conduce a excelentes resultados. El empleo de moldes cerámicos facilita la construcción al evitar encofrados, aligera las masas, manteniendo en ellas un elevado momento de inercia, y coadyuva a resistir los esfuerzos a que está sometida la "dovela-onda", muy especialmente los secundarios. Nuestra gran experiencia en la construcción de gran número de bóvedas onduladas, varias de ellas de $35 \mathrm{~m}$ de luz, nos ha confirmado plenamente que esto, en realidad, sucede asi.

La figura 12 nos muestra una sección transversal de una "dovela-onda" correspondiente a una bóveda de $35 \mathrm{~m}$ de luz. $\mathrm{Su}$ espesor es de $8 \mathrm{~cm}$, distribuídos en $6 \mathrm{~cm}$ para altura de las piezas cerámicas y $2 \mathrm{~cm}$ para el recubrimiento de mortero de hormigón. 

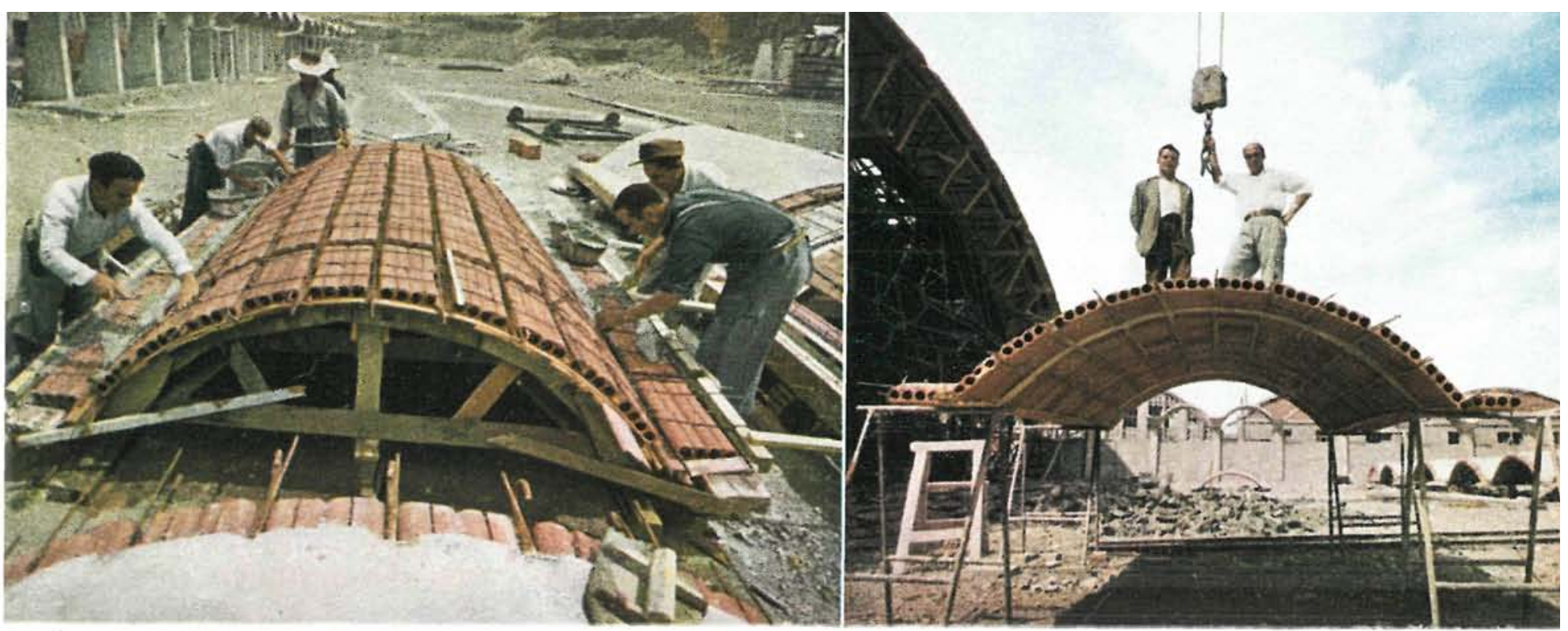

La figura 13 es una sección longitudinal por la clave. La figura 14 es una perspectiva de una dovela-onda, sin hormigonar totalmente, preparada para su elevación, correspondiente a la bóveda de un hangar de $100 \mathrm{~m}$ de luz, cuyo estudio nos encomendó una firma alemana, pudiendo, por lo tanto, el lector darse perfecta cuenta del dispositivo estructural de dichos elementos. Completa la ilustración la figura 15, que es la fabricación de una "dovela-onda" de $3 \times 4 \mathrm{~m}$ y $8 \mathrm{~cm}$ de espesor $(6+2)$, con la que se pueden lograr luces de 45 metros.

De su examen se desprende que, debido a la colocación de las piezas cerámicas (prescindamos de los nervios de rigidez, de los que hablaremos más adelante), la "dovelaonda" no ofrecería ninguna resistencia transversal en cuanto a su abertura, por no poder colocar ninguna armadura en su parte inferior, no así en cuanto a su cierre que lo impiden los hierros circulares colocados en la parte superior.

Es evidente, que al poder considerar la bóveda ondulada como suma de los "arcos-onda", con estabilidad independiente, el cálculo de la cubierta puede reducirse al de uno de estos elementos que, a su vez, está formado por el acoplamiento de las "dovelas-onda", perfectamente enlazadas unas con otras por el hormigonado de los hierros salientes unidos por ganchos, ataduras o soldaduras, formando empalmes eficaces.

En el trabajo elástico del "arco-onda", cada "dovelaonda" tomará el que le corresponde, que se traducirá en unas deformaciones producidas, principalmente, por las compresiones normales y flexiones producidas por los momentos en cada sección. Indudablemente, una de esas deformaciones será de abertura y cierre de la onda. Es, por lo tanto, preciso dar a la "dovela-onda" elementos resistentes que se opongan a ellas.

\section{Nervios de rigidez}

De aquí nació la necesidad de crear "los nervios de rigidez" que, por otra parte, eran también precisos para hacerlas indeformables para su fácil manejo por grúas.

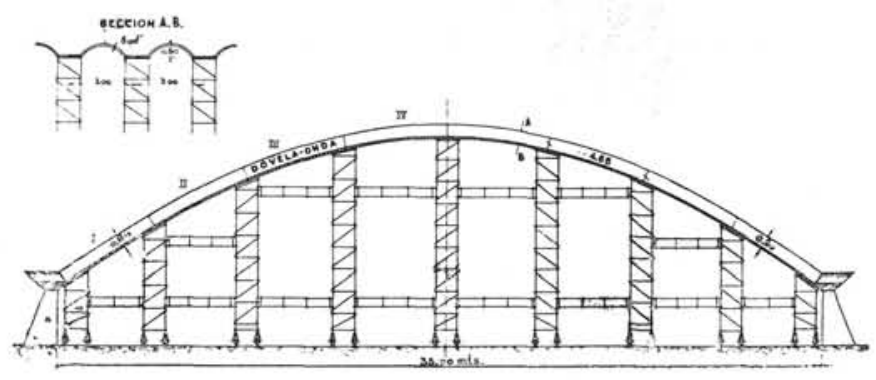

17
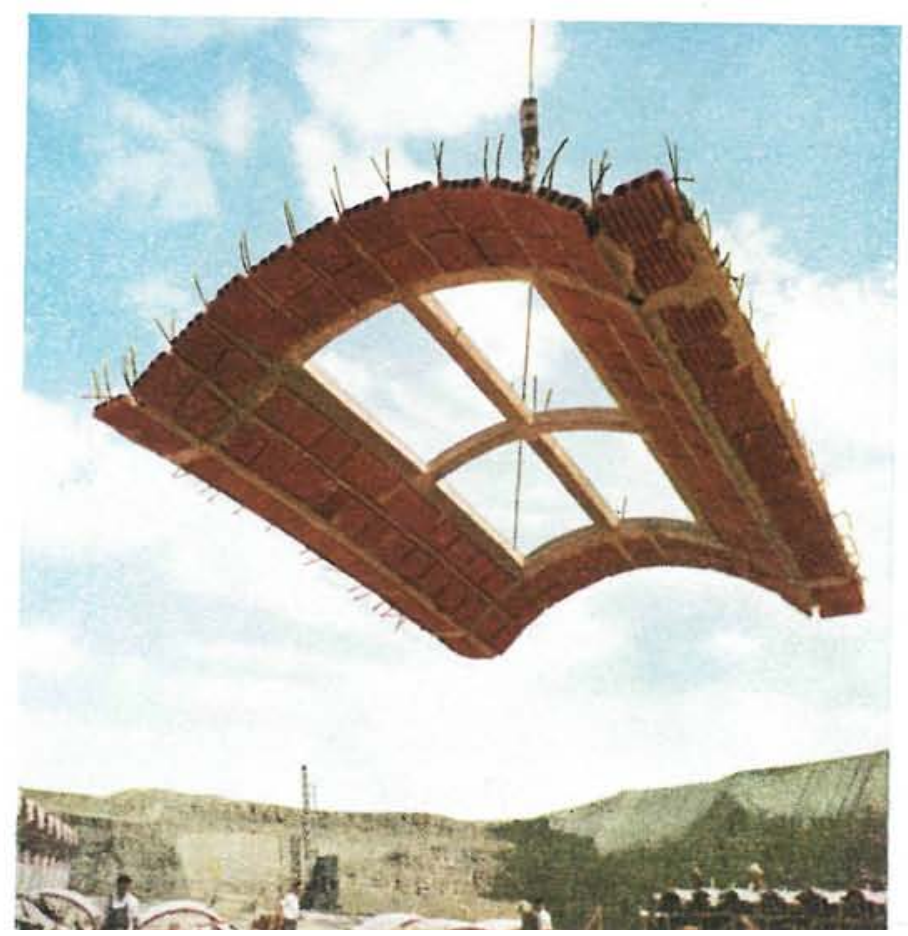
En las figuras ya aludidas $(13,14,15)$ se ve claramente la disposición dada a estos elementos esenciales de las "dovelas-onda". En general, son suficientes dos, colocados cerca de los extremos con el fin de dar una perfecta estabilidad a la dovela cuando es alzada por la grúa, ya que las horquillas de enganche van colocadas en ellos. En la sección (figura 13) están dibujados los nervios de rigidez, los moldes o piezas cerámicas y los hierros de empalme entre dovelas, todo lo cual se comprueba en la figura 15, que corresponde a un momento de su fabricación. Ahora bien; era muy conveniente que estos nervios de rigidez de hormigón no rompiesen la continuidad superficial de la bóveda principalmente bajo el aspecto estético, que por su multiplicidad, en una gran longitud, tanto interior como exteriormente, no sería agradable. Esta dificultad quedó pronto resuelta, porque vimos, mediante unos sencillos cálculos, que su altura, en todos los casos, podía ser igual al espesor de las dovelas, y, por lo tanto, resultar invisibles, circunstancia en extremo feliz que la práctica sancionó, como puede comprobar el lector por el examen de las fotografías que ilustran este trabajo.

Ahora bien; ¿para qué clase de solicitaciones o para qué clase de cargas deben calcularse estos nervios de rigidez? En este caso, nuestra intuición-esa intuición (cierta o equivocada) que tiene todo ingeniero de la manera de sentir su obra-nos hizo aceptar, como un máximo, para el trabajo transversal de una "dovela-onda", el que correspondería a un pórtico de esa forma apoyado libremente sobre rodillos ideales bajo sus aletas, sometido a su peso propio y sobrecargas de viento y nieve. Pero luego, con un espíritu de economía, que también debe tener todo ingeniero, decidimos considerar solamente su peso propio, ya que, por otra parte, éste era el que realmente nos interesaba tener en cuenta para que las "dovelas-onda" pudiesen ser elevadas y fuesen estables apoyadas sobre la cimbra en 4 puntos.

De este modo se calcularon los nervios de rigidez, a reserva, claro está, de los resultados que dieran los ensayos sobre el modelo reducido. Una vez más, nuestra intuición, como veremos, nos fué fiel.

Las dovelas así fabricadas son de una gran rigidez, lo que permite, con toda seguridad, su transporte y elevación por grúas (figuras 16 y 18) y la simplificación de las cimbras que pueden reducirse a sencillos castilletes (fig. 17) que sirvan de apoyo a 4 puntos de la "dovela-onda".

Nuestra ya gran experiencia en 20 bóvedas-onduladas construídas (varias con luces de $35 \mathrm{~m}$ ), con muchos cientos de "dovelas-onda" fabricadas del modo mencionado, ha confirmado que nuestro punto de vista era correcto. El modelo reducido nos dió también su aprobación, pero para realizaciones de mucha mayor envergadura.

\section{Procedimientos de cálculo seguidos}

Poco tenemos que añadir a lo dicho para que el lector se dé cuenta perfecta del procedimiento a seguir para la construcción de una bóveda de esta clase. Réstanos únicamente, justificar los procedimientos de cálculo seguidos por nosotros, así como la serie de ensayos realizados para investigar, sobre un extraordinario modelo reducido, los efectos de las cargas en las deformaciones de un "arco-onda".

Hemos visto que una bóveda ondulada está formada por el acoplamiento o suma de varios "arcos-onda" (figs. 10 y 11 ). Nuestra primera simplificación consiste en que, como estos "arcos-onda" tienen estabilidad propia independiente, el cálculo de la bóveda queda reducido al de uno de estos elementos. Pues bien, esto ha sido totalmente sancionado por la realidad, en una cubierta ondulada de características y dimensiones excepcionales: $150 \mathrm{~m}$ de longitud por $35 \mathrm{~m}$ de luz y $8 \mathrm{~cm}$ de espesor de bóveda aligerada con piezas cerámicas de $25 \times 25 \times 6 \mathrm{~cm}$. Y decimos sancionado por la realidad, porque, en efecto, ella se ha encargado de demostrarnos, en una obra de tales características, que la yuxtaposición con perfecto enlace por cruzamientos de hierros y esmerado hormigonado, de nada menos que de cincuenta "arcos-onda", de $3 \mathrm{~m}$ de anchura, no ha ocasionado en la bóveda la más mínima perturbación producida por las dilataciones de temperatura. Es decir, que ha trabajado como un perfecto acordeón, soportando imperturbable las altas temperaturas del verano de 1957. Bien es cierto que la bóveda, a que hacemos referencia, tiene sus arranques materializados en puntos sobre los contrafuertes (figs. 19 y 20) que no la coaccionan en su libre dilatación, en vez de hacerlo sobre vigas corridas laterales (figs. 23 y 24) que ejecutamos en nuestras primeras bóvedas.

Debemos señalar que intuitivamente estos resultados los habiamos previsto, y después de muchas dudas e indecisiones optamos por no realizar ninguna junta de dilatación en esta gran cubierta de $150 \mathrm{~m}$ de longitud, aunque también se había previsto su corte transversal, operación q ie podía efectuarse con gran facilidad, siguiendo una generatriz, clave, a lo largo de un "arco-onda".

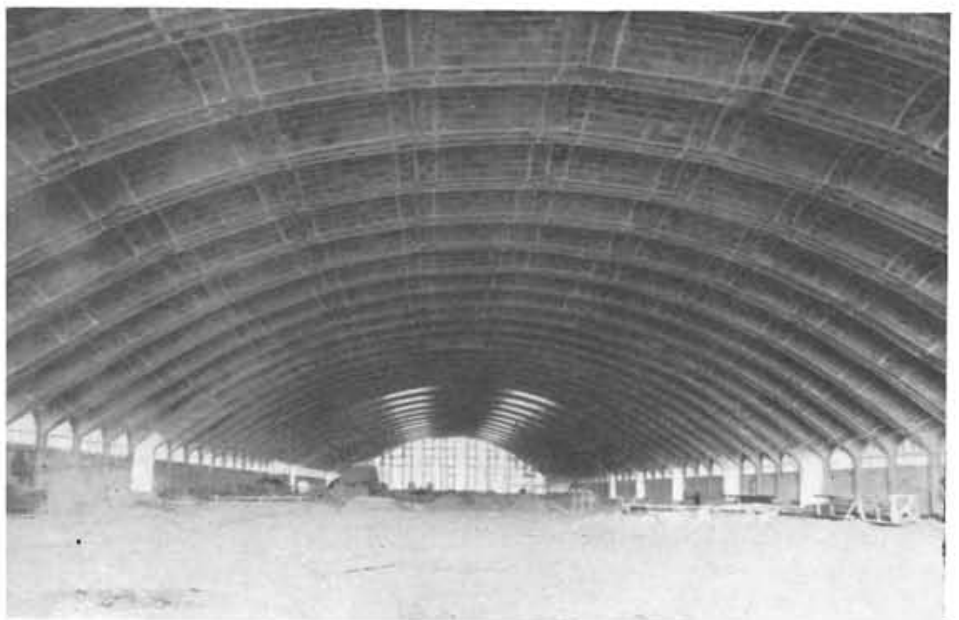

19

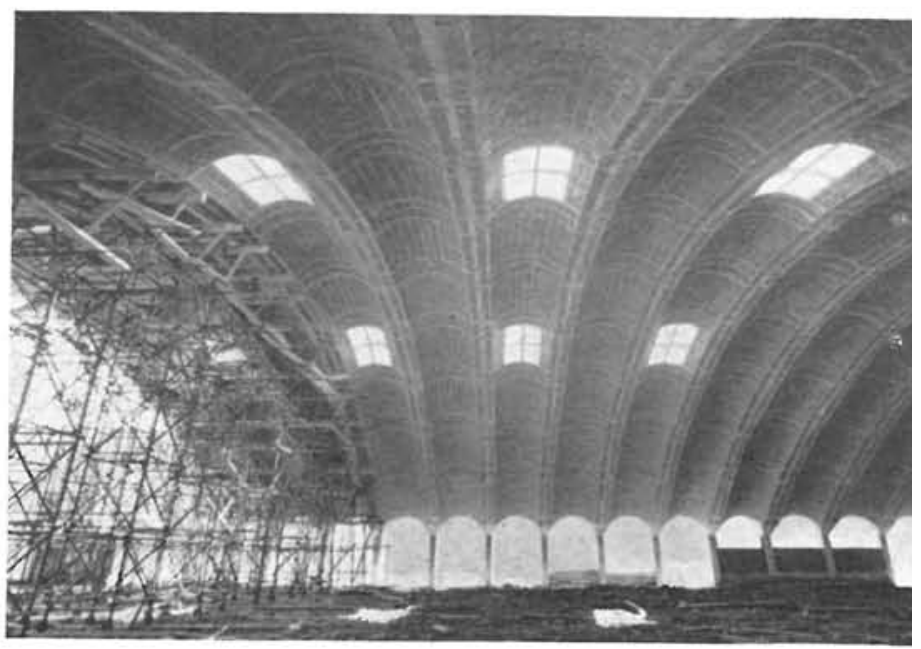




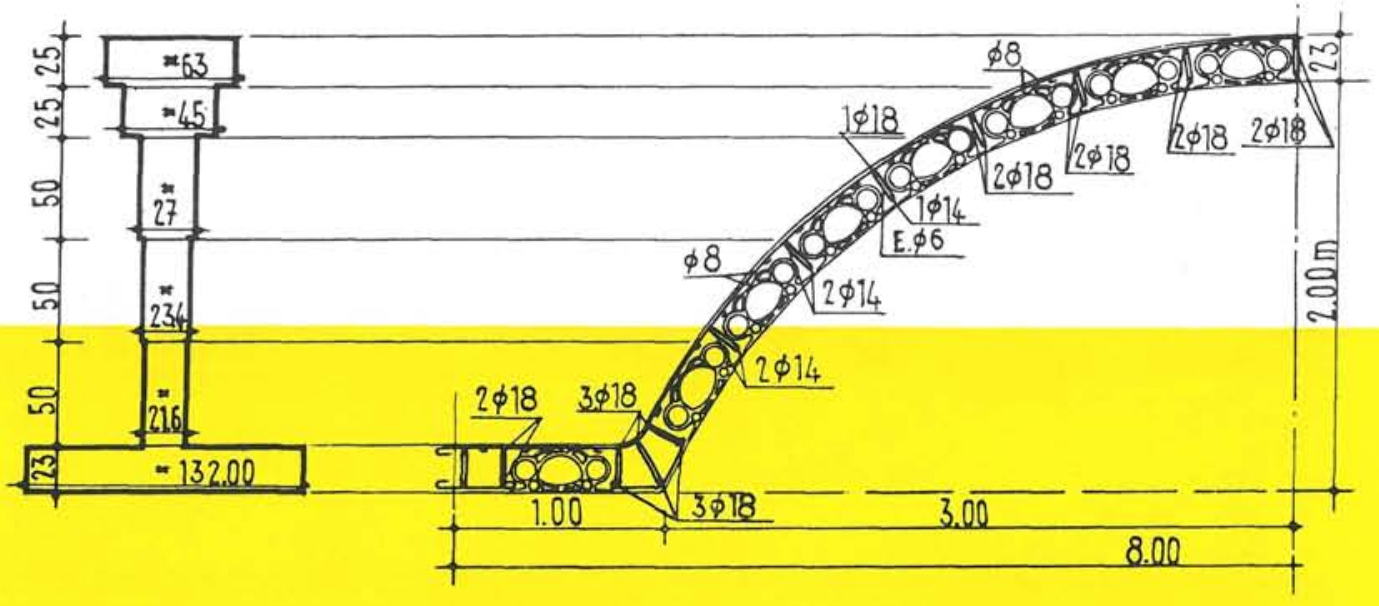

Por esta singular elasticidad longitudinal, tipo acordeón, se ha demostrado y comprobado, por un detenido examen sobre las diversas realizaciones llevadas a efecto, que favorece en grado elevado la impermeabilización de la cubierta por no aparecer grietas en la superficie, a lo que, indudablemente, coadyuva su gran rigidez transversal producida por el ondulado. Entre las diversas notas agradables que este nuevo tipo de construcción nos ha producido, ha sido ésta una de ellas y no la de menor importancia.

Es evidente, que si el "arco-onda" que, en definitiva, es a lo que ha quedado reducido el cálculo de la bóveda, no estuviera integrado de la forma que está y fuese su masa más homogénea, ahí tendríamos a nuestros admirados colegas-matemáticos entendiéndoselas con todo el complicado bagaje de sus ecuaciones diferenciales. Pero, en nuestro caso, creemos que esas ecuaciones no pueden formularse a la vista de la estructura de las "dovelas-onda". Nos encontramos, por consiguiente, ante un problema de ingeniería, cuya solución tiene que darla el ingeniero con visión clara del problema mecánico.

Si, por primera vez, nos dieran una viga en doble $\mathrm{T}$ de ala ancha, sometida a flexión, para estudiar las reacciones en sus diferentes puntos, nos entrarían unas grandes dudas acerca de lo que sucedería en los bordes de las alas. Pero, vemos que se calculan muy fácilmente admitiendo una rígida transmisión de deformaciones entre el alma y las cabezas y una uniforme repartición de tensiones a lo largo de ellas, dentro de ciertos límites, para lo cual nos basta considerar sus momentos de inercia, como si las masas de las alas estuviesen concentradas en los extremos del alma. Sabemos, sin embargo, que existe una ley de transmisiones de deformaciones y tensiones a lo largo de las alas que no es práctíco tenerla en cuenta, como que existe otra ley más correcta que la deformación plana, que no es necesaria para el cálculo. Sucede lo mismo en la sección de nuestro "arco-onda". En efecto; si la suponemos dividida en dos partes por la recta paralela a las alas, que pasa por su centro de gravedad, por efecto de un momento la parte inferior, por ejemplo, trabaja a tracción y la superior a compresión, siendo la mencionada recta el eje neutro. Ahora bien; como esta sección va convenientemente armada para que en toda ella se transmitan las deformaciones (no olvidemos los nervios de rigidez), podemos admitir la hipótesis de una concentración o traslación de su masa sobre el eje, normal a las aletas, que pasa por el centro de gravedad. Tendríamos así, convertida la "onda" en una sección de viga de alma variable (fig. 21) y el "arco-onda" convertido en un nervio con esa sección; cuya comprobación mecánica del trabajo del hormigón y hierro se realizaría por los procedimientos conocidos correspondientes al arco empotrado, con la correspondiente comprobación gráfica de las secciones a flexión compuesta.

Sin embargo, nuestro espíritu intuitivo no podía quedar completamente tranquilo porque, si bien hemos metamorfoseado nuestra onda para convertirla en una sección que admitimos mecánicamente equivalente, esto en realidad es, hasta cierto punto, porque lo que existe es la onda, y no el nervio, y su trabajo tiene unas características bidimensionales que no tiene éste. Por esto, desde el primer momento se presiente una deformación de la onda en el sentido de abertura y cierre producidos, principalmente, por un momento flector. Como ya hemos visto que el enfoque matemático es inaplicable, sólo nos quedó el recurso de los ensayos en modelos reducidos, y a ellos fuimos decididos a hacerlos con toda la precisión posible para poder obtener resultados aprovechables que nos orientasen acerca de la amplitud de dichas deformaciones y, como consecuencia, de la intensidad de los esfuerzos a que transversalmente está sometida la onda.

\section{Ensayos sobre modelos reducidos}

Primera pregunta que nos hicimos: ¿Qué es lo que vamos a ensayar? Consecuentes con el fin principal de este trabajo, que es el desarrollo de una idea para la construcción de grandes bóvedas, hemos elegido para nuestro objeto el modelo reducido correspondiente a un proyecto de hangar de 100 metros de luz, cuya perspectiva corresponde a la figura 22. Por otra parte, una luz semejante permite su utilización para salones de exposiciones, palacios de deportes, etc. Aceptado esto, nos faltaba precisar las dimensiones o escala del modelo reducido. No dudamos en fijar para él unas dimensiones suficientes para poder realizar, con garantías de éxito, los ensayos y comprobaciones pertinentes. Así es que dimos por bueno un modelo a escala 1/10, en cuyo caso la luz del "arco-onda", de dicho modelo, tendria: DIEZ METROS.

Ya se comprenderá la importancia que iba a tener, y la calidad de las observaciones y resultados que podrían obtenerse. Como el proyecto de hangar lo teníamos estudiado, disponíamos, por lo tanto, de sus elementos dimensionados; todo era cuestión de reducirlos automáticamente a la referida escala de $1 / 10$. 


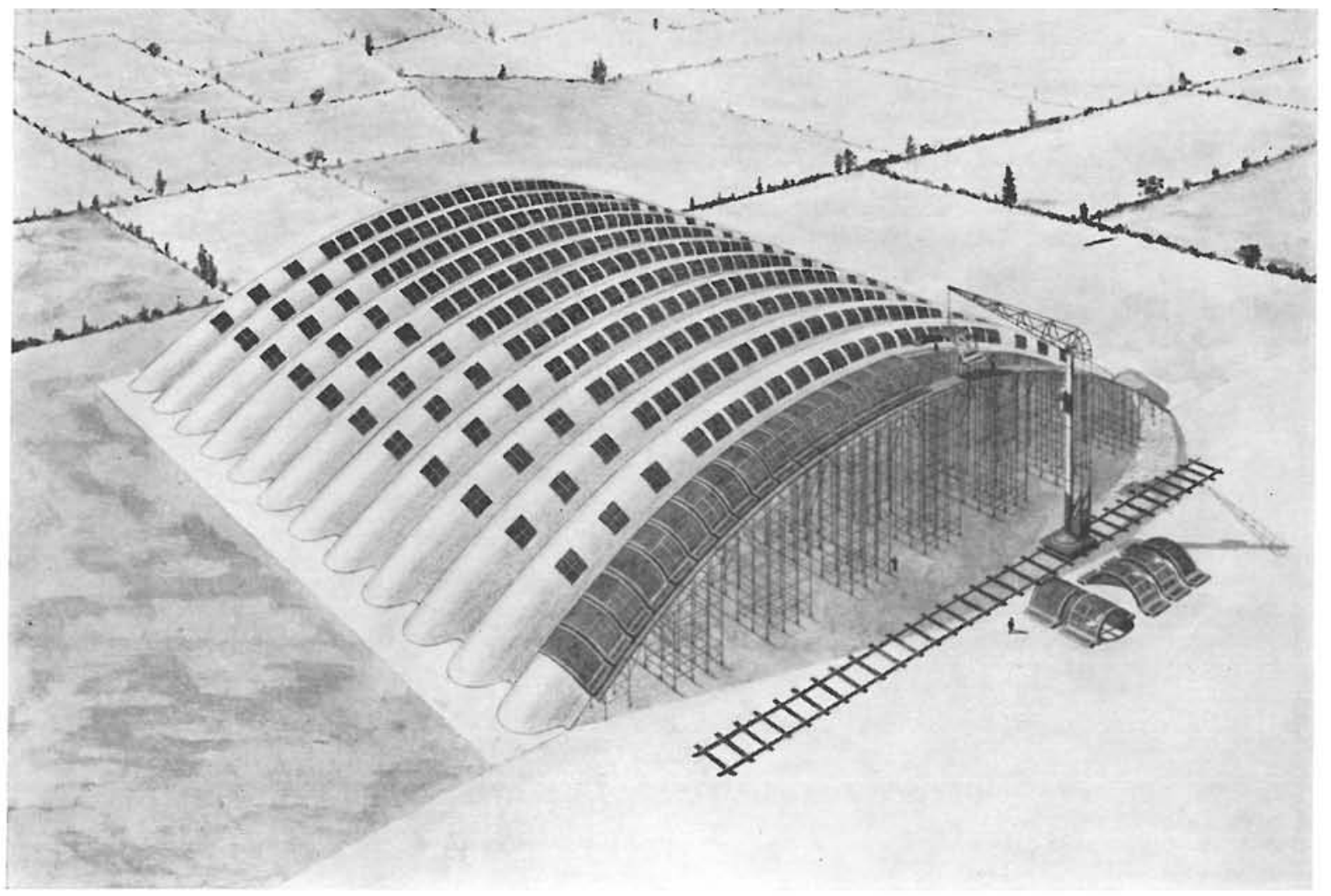

Las características de la bóveda ondulada del hangar, con arranques desde el terreno, eran las siguientes: Luz: 100 metros. Ancho de la onda: 8 metros. Altura de la onda: 1,90 metros. Espesor: 0,25 metros. Altura de piezas cerámicas: 0,22 metros. Recubrimiento de hormigón: 0,03 metros. Ancho de las piezas: 0,50 metros.

Citaremos como dato de interés, que la construcción de este modelo requirió la fabricación, en una planta piloto, de 12.000 pequeñas piezas cerámicas, a rigurosa escala de las verdaderas, con dimensiones de $22 \times 50 \times 50 \mathrm{~mm}$. Las armaduras fueron alambres de $0,5 \mathrm{~mm}, 2,2 \mathrm{~mm}$ y $2,4 \mathrm{~mm}$, cuya colocación tuvo que ser esmeradísima porque, dados los pequeños espacios disponibles, presentó serias dificultades. Lo mismo sucedió con el hormigonado, para el que se seleccionaron, con cribas finas, gravillas de tamaño máximo de $5 \mathrm{~mm}$. La dosificación fué de $350 \mathrm{~kg}$ de cemento. La figura 23 corresponde a la del modelo con las piezas cerámicas antes de la colocación de los alambres. En ella se aprecian perfectamente los espacios dejados, cada $40 \mathrm{~cm}$, que corresponden a los nervios de rigidez.

Los ensayos fueron encomendados al Laboratorio Central de Ensayo de Materiales de la Escuela de Ingenieros de Caminos y dirigidos por el Profesor de la Escuela, Carlos Benito. Veintitrés flexímetros, convenientemente colocados en el modelo, fueron instalados por el Laboratorio (fig. 24), con precisión en sus mediciones de un 1,100 milímetros.

Para la prueba se prepararon sacos de arena de $50 \mathrm{~kg}$ (figura 25).

Se deseaba conocer, principalmente, las flechas obtenidas por el "arco-onda", ante las diferentes solicitaciones de cargas de sacos, así como las medidas de las aberturas y cierre de la onda, o sea, los corrimientos horizontales. Es decir, que se quería comprobar el comportamiento mecánico y elástico

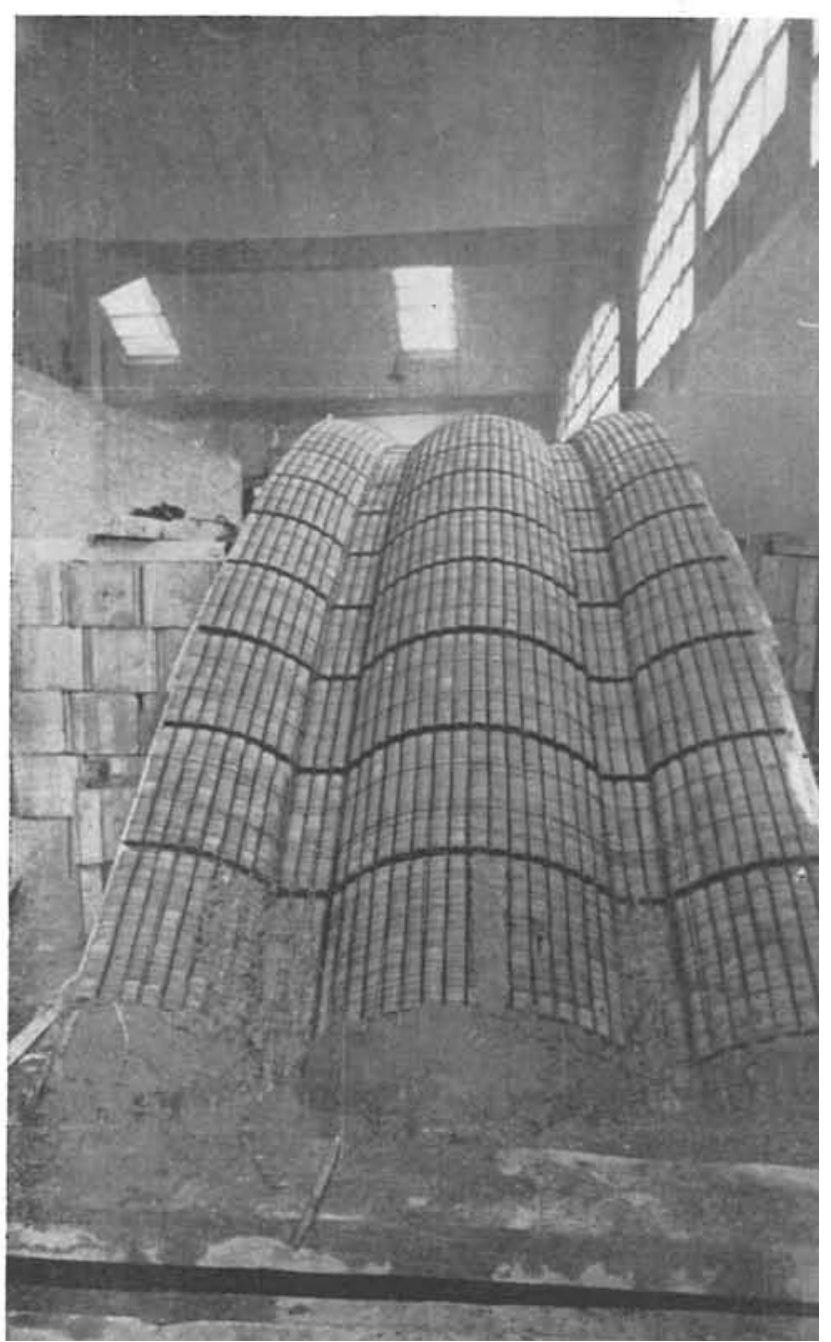




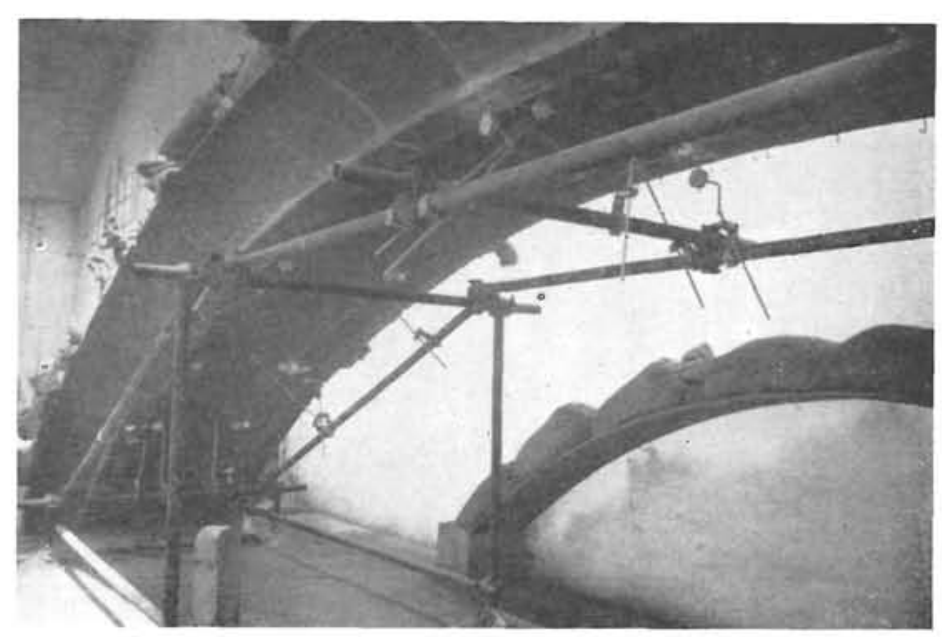

24

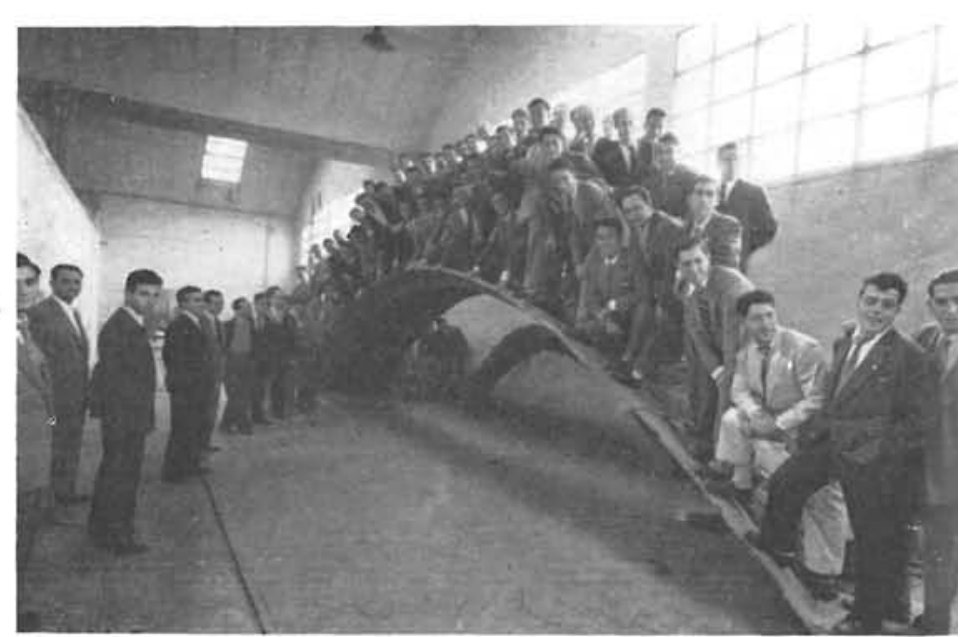

25

del "arco-onda", reforzado transversalmente por los nervios de rigidez correspondientes a las diversas "dovelasonda" y calculado en la forma simplificada, con la sección en $\mathrm{T}$ de alma variable equivalente (fig. 21). Los nervios de rigidez se dimensionaron de modo a garantizar la estabilidad de las dovelas, supuestas apoyadas sobre cuatro puntos, situados en sus aletas en la forma que claramente se aprecia en las figuras 16 y 17.

Se comprende la gran importancia de estas comprobaciones, pues de ellas podría depender que nuestro procedimiento de cálculo pudiera ser aplicable. Veremos después que, a pesar de los resultados en extremo favorables de los ensayos sobre el modelo, se han continuado sobre un "arco-onda", aislado, de una obra real, de 35 metros de luz.

Vamos a resumir, brevemente, por ser de gran interés, los resultados obtenidos en los ensayos, sobre el mencionado modelo reducido de un arco de $100 \mathrm{~m}$ de luz, realizados por el Laboratorio Central de la Escuela de Ingenieros de Caminos. La sección ensayada es la esquemática, $\_$_ $~-$, que corresponde a un "arco-onda" cuya cuerda o luz es de $640 \mathrm{~mm}$, con dos semiarcos laterales. Aceptamos esta sección, para ver su comportamiento conjunto, arco y semiarcos, pues es indudable que los resultados que se obtendrían iban a ser más reales que los del ensayo de un solo "arco-onda" aislado, que trabaja en condiciones más desfavorables.

Se midieron desplazamientos verticales o flechas y corrimientos horizontales, correspondientes a la abertura y cierre de onda, con flexímetros colocados convenientemente (fig. 24). Previamente se colocó sobre el modelo una carga permanente de $4.400 \mathrm{~kg}$, equivalente a la diferencia de pesos entre el modelo y el correspondiente de la sección real, para colocarlos en las mismas condiciones de carga. Con dicho peso, que permaneció invariable, se procedió a realizar las pruebas con sobrecargas adicionales de 125 y $200 \mathrm{~kg} / \mathrm{m}^{2}$. La carga adicional uniformemente repartida a razón de $200 \mathrm{~kg} / \mathrm{m}^{2}$, dió los siguientes resultados medios-máximos, después de efectuar la prueba varias veces:

$$
\begin{aligned}
& \text { En flechas o desplazamientos verticales ..... }+0,4 \mathrm{~mm} \text {. } \\
& \text { En abertura de onda } \ldots \ldots \ldots \ldots \ldots \ldots \ldots \ldots+0,1 \mathrm{~mm} \text {. }
\end{aligned}
$$

La carga colocada sobre medio arco, a razón de $125 \mathrm{~kg} / \mathrm{m}^{2}$, superior a la corrientemente admitida, de $100 \mathrm{~kg} / \mathrm{m} 2$, para cubrir la acción del viento y nieve, produjo:

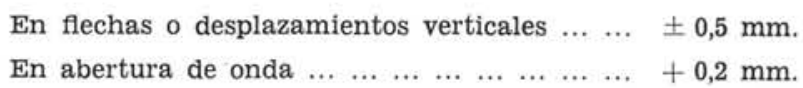

Tendremos las siguientes relaciones:

Para el arco de $10 \mathrm{~m}$ de luz:

$$
\begin{aligned}
& \frac{\text { flecha }}{\text { luz }}=\frac{0,5 \mathrm{~mm}}{10.000 \mathrm{~mm}}=\frac{1}{20.000} \\
& \frac{\text { abertura }}{\text { luz }}=\frac{0,2 \mathrm{~mm}}{640 \mathrm{~mm}}=\frac{1}{3.200}
\end{aligned}
$$

Resultados sumamente favorables, en los cuales, sin duda, han influido la calidad del modelo ensayado $y$ el perfecto empotramiento de los arranques del arco. 


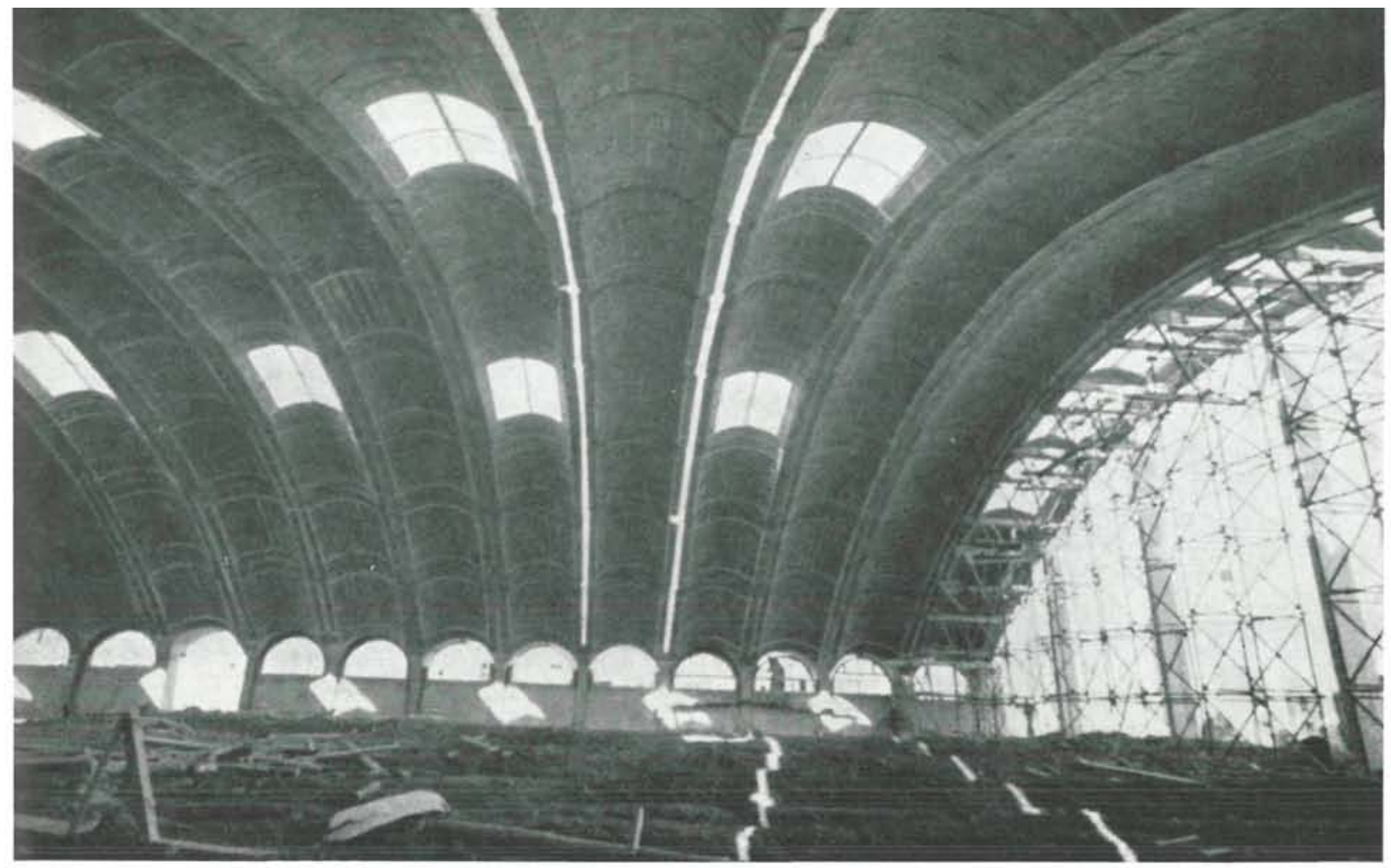

$26 a b$ y $c$

Visto el gran número de sacos que se hubiera necesitado para la rotura-que de momento no teníamos-y la simpatía y gratitud que tomamos al modelo por su perfecto comportamiento (no podíamos olvidar tampoco su calidad), le indultamos de la pena capital, de cargarlo hasta la rotura, ya que, por otra parte, como nos demuestra la impresionante fotografía de la figura 25 , nos iba a servir para efectuar en él las pruebas dinámicas que, en lo sucesivo, correrían a cargo de las variadas y polifacéticas promociones de alumnos de las Escuelas Especiales de Arquitectos, Ingenieros, Ayudantes, etc. La de la fotografía corresponde a la de la inauguración de esta clase de pruebas, que le cupo el honor de llevarla a buen fin a una heroica promoción de 70 alumnos de la Escuela de Ayudantes de Obras Públicas, con su ilustre profesor, Carlos Benito, dando ejemplo...

En cambio, y como contraste, el modelo reducido de 4 metros de luz, correspondiente a uno normal de 40 metros, de generatriz recta, que se aprecia en el fondo de la fotografía (fig. 24) debajo del arco ondulado, construído con las mismas piezas cerámicas, e igualdad de armaduras, no permitió superar la carga de cálculo por el inminente peligro de pandeo. Para éste no hubo ningún decidido que se prestase a realizar una prueba dinámica...

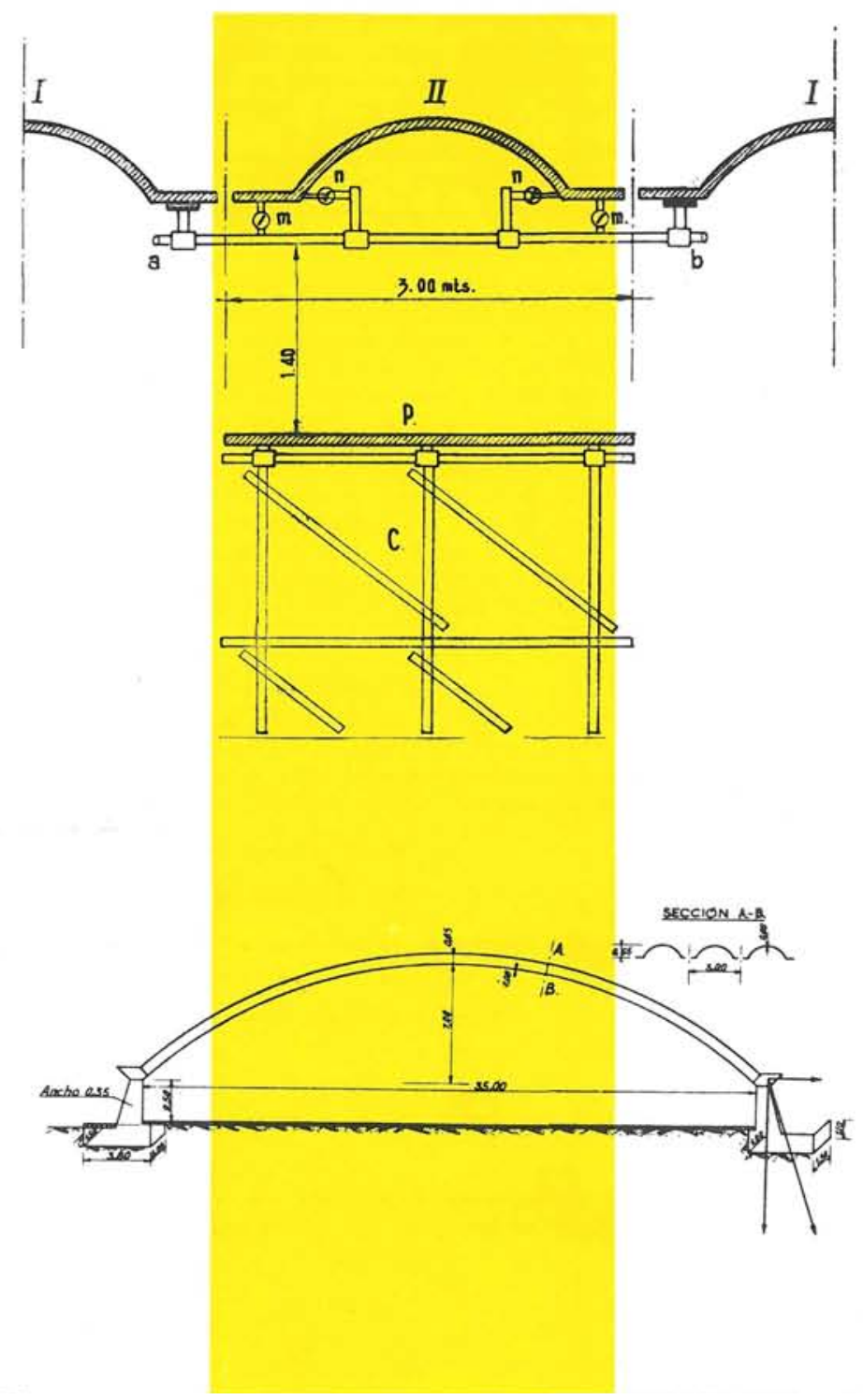




\section{Ensayos sobre un "arco-onda" de $35 \mathrm{~m}$ de luz}

Se aprovechó la oportunidad tenida durante la construcción de la bóveda ondulada de Río-Cerámica, de características excepcionales debido a sus dimensiones de $150 \times 35 \mathrm{~m}$, para hacer unos nuevos ensayos acerca del comportamiento elástico del conjunto: "arco-ondacontrafuertes-cimientos".

Es decir, una prueba que afectaba a más elementos que la realizada en el modelo reducido, en el que el "arco-onda" tenía sus arranques perfectamente empotrados en el terreno. Resultaba de gran interés conocer sus resultados, complementarios de los obtenidos en la primera prueba $y$, en particular, por tratarse de una obra real, muy corriente, cual es la de una bóveda con contrafuertes.

La prueba comenzó por aislar uno de los 50 "arcosonda" que integran la cubierta (fig. 26a) para someterlo a una carga uniformemente repartida, sobre medio arco, a razón de $100 \mathrm{~kg} / \mathrm{m}^{2}$, con 10 cual quedaban cubiertas con exceso las acciones que pudieron ejercer sobre la bóveda el viento y la nieve. Esta operación se llevó a efecto fácilmente, aprovechando los elementos tubulares empleados en la construcción de la bóveda, y como máxima garantía se encomendó, nuevamente al Laboratorio Central de la Escuela de Ingenieros de Caminos, la realización de los ensayos, cuyo esquema se representa en la figura $26 \mathrm{~b}$, en el que se observa el conjunto ensayado "arco-contrafuerte-cimientos", y el detalle de la colocación de los flexímetros (se emplearon 20 de una precisión de $1 / 100 \mathrm{~mm}$ ) distribuídos en la proximidad de los arranques, riñones y clave.

Se procedió a colocar y quitar durante cinco veces consecutivas la carga de $100 \mathrm{~kg} / \mathrm{m}^{2}$ sobre medio arco, previa lectura de los instrumentos de medida, que acusaron recuperaciones casi totales de las deformaciones.

Los valores máximos de estas cinco repeticiones de la carga correspondieron a las secciones próximas al $1 / 4$ de la luz, y fueron:

Corrimientos verticales del "arco-onda":

$$
\frac{\text { Corrimiento vertical }}{\mathrm{Luz}}=\frac{9,1 \mathrm{~mm}}{35.000 \mathrm{~mm}}=\frac{1}{3.950}
$$

Corrimientos horizontales de la onda:

$$
\frac{\text { Máxima abertura }}{\mathrm{Luz}}=\frac{2,1 \mathrm{~mm}}{2.200 \mathrm{~mm}}=\frac{1}{1.050}
$$

Observando la figura $26 \mathrm{~b}$, vemos que estos resultados afectan a los totales desplazamientos que haya podido tener el conjunto "arco-onda-contrafuertes-cimientos", puesto que es evidente que una pequeña deformación del terreno por el empuje del arco a través de los contrafuertes se traducirá en un aumento de su luz, incrementando, en consecuencia, todos los desplazamientos. Por esto, habiendo existido recuperaciones casi totales, como muestra la figura $26 \mathrm{c}$, los resultados obtenidos pueden considerarse como excelentes. Debiendo advertir que la prueba del "arco-onda" se hizo a los veinte días de su ejecución, ya que no podía aplazarse por más tiempo la terminación de la nave para la industria "Río-Cerámica".

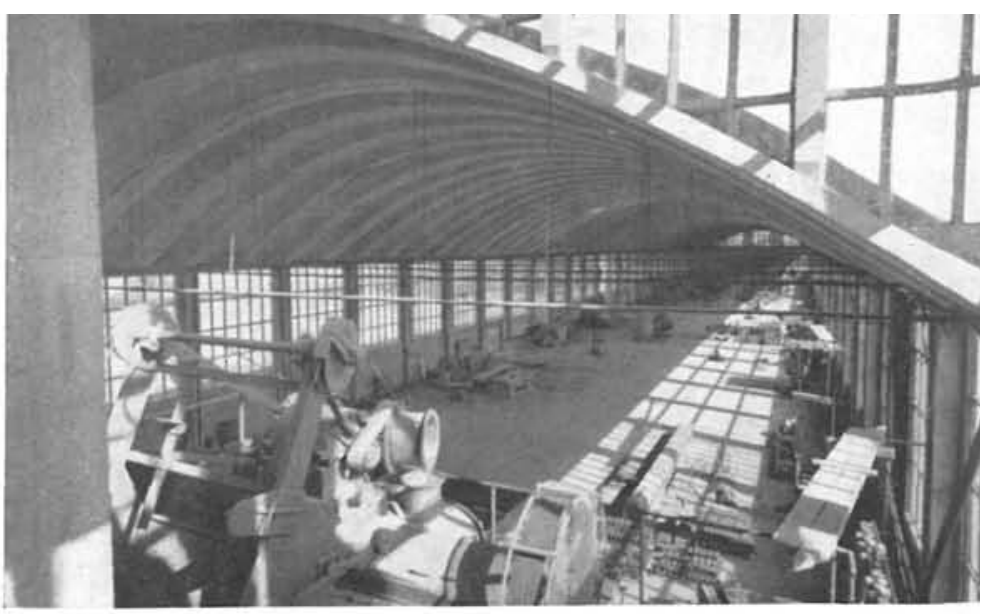

28
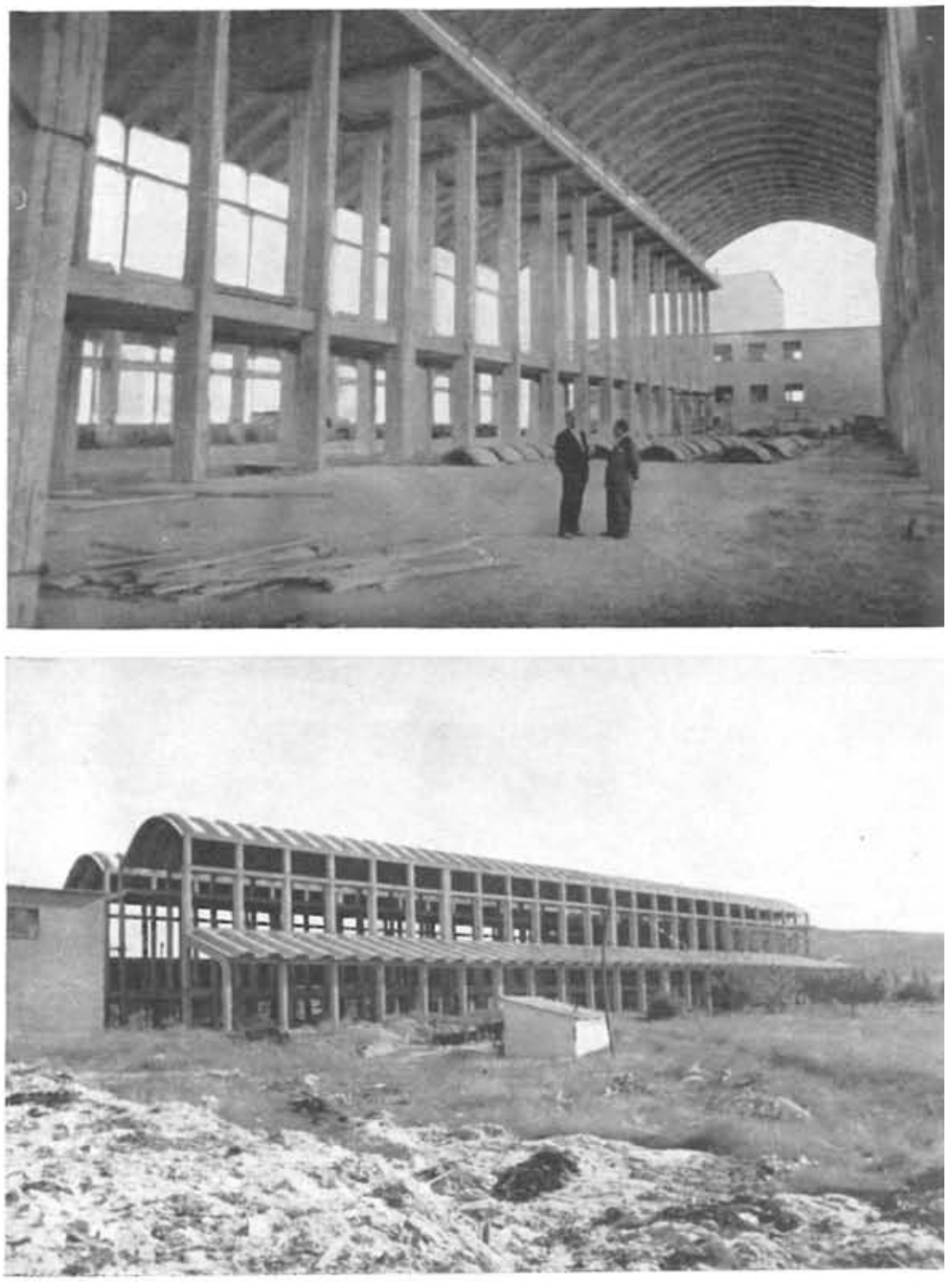

29

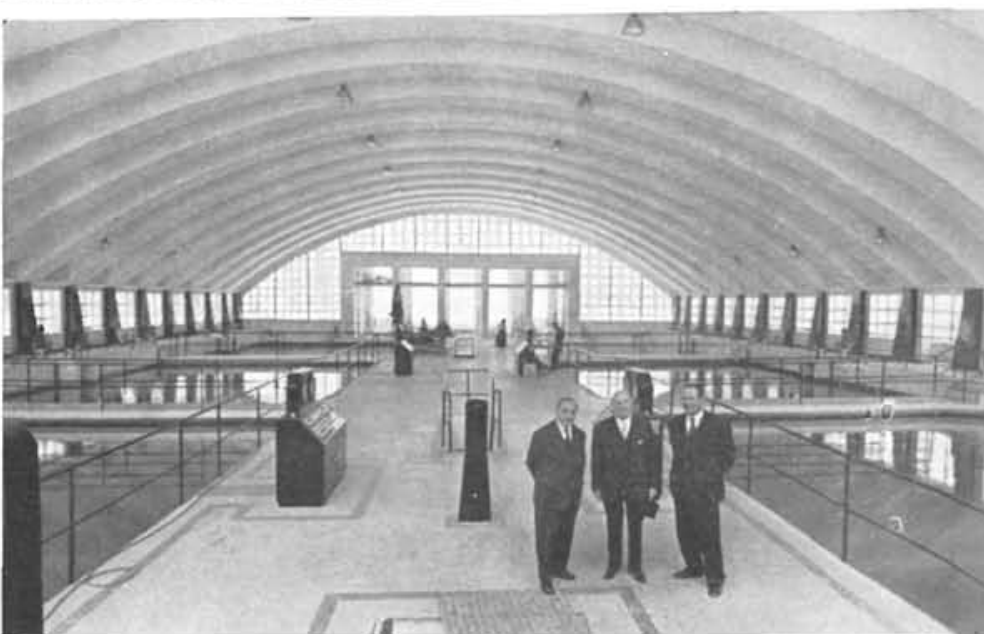




\section{Bóvedas onduladas construidas}

Como consecuencia de los resultados en extremo favorables obtenidos en el modelo reducido, no dudamos en llevar a la práctica el nuevo sistema. La primera bóveda realizada (fig. 27), de $20 \mathrm{~m}$ de luz y $160 \mathrm{~m}$ de longitud, tiene las siguientes características:

Bóveda con tirantes y rebajamiento: $1 / 5$.

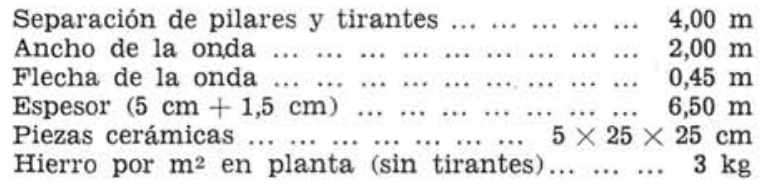

Debemos llamar la atención acerca del pequeño espesor de la cubierta, que era de $6,5 \mathrm{~cm}$, de los cuales corresponden: $5 \mathrm{~cm}$ a las piezas cerámicas y $1,5 \mathrm{~cm}$ al recubrimiento de mortero, así como también al muy reducido empleo de hierro, que fueron alambres de 5 milímetros.

La impermeabilización de la cubierta se logró muy fácilmente, con dos capas de alquitrán, debido a la gran rigidez transversal de estas cubiertas y a las vertientes rápidas de la doble curvatura.

La segunda bóveda ondulada, se ha construído para cubrir unos grandes almacenas de paja en Miranda de Ebro.

Dadas las singulares características de esta obra, de $120 \mathrm{~m}$ de longitud y $60 \mathrm{~m}$ de ancho total, correspondiente a dos naves centrales y dos pórticos laterales, de $8,40 \mathrm{~m}$, para servicio de ferrocarril y, en particular, la altura de los arranques de la cubierta, a $20 \mathrm{~m}$, resultó sumamente indicado el empleo de "dovelas-onda", que por sus dimensiones, de $2 \times 1,60 \mathrm{~m}$ y peso de elevación de $320 \mathrm{~kg}$, facilitaron extraordinariamente la construcción de la cubierta. La figura 28 nos muestra el interior de esta nave, en la que se ven preparadas varias "dovelas-onda".

No podemos dejar de mencionar la solución dada a la cubierta en vertiente, de los pórticos laterales. Es una consecuencia lógica de la gran rigidez que presentan las "dovelas-onda" y que hemos aprovechado para salvar el vano de $8 \mathrm{~m}$ para cubrirlos, mediante el empalme recto de varias "dovelas-onda" de las mismas dimensiones que las empleadas en las bóvedas. Fué suficiente reforzar el hierro de las aletas para resistir las tensiones que en ellas se producen. Solución feliz, por la grata armonía que producen los dos ondulados, como se aprecia en la vista general de la obra (fig. 29).

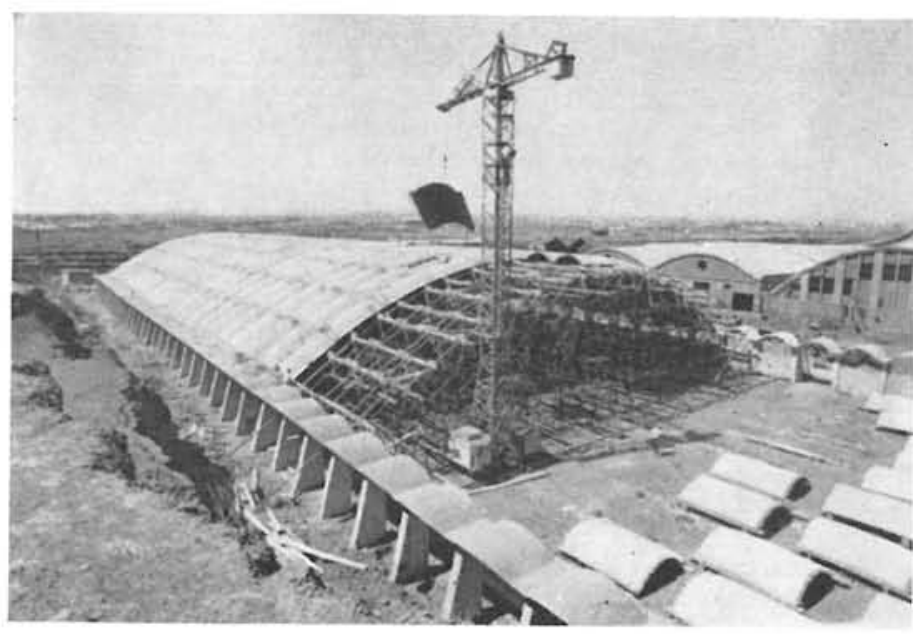

31

La tercera bóveda construída, para la Factoría de F. E. F. A. S. A., ha sido de $30 \mathrm{~m}$ de luz, sin tirantes. Los empujes se compensaron con contrafuertes de hormigón armado. La figura 30 es una vista interior de la estación depuradora de aguas, en la que se destaca perfectamente el ondulado de la bóveda y los contrafuertes. Tiene un espesor de $8 \mathrm{~cm}=6+2$ y el peso del hierro por $\mathrm{m}^{2}$ en planta es de 8 kilogramos.

\section{Espesores}

Debemos indicar, acerca de los espesores que en la práctica conviene dar a estas bóvedas-onduladas, que los que se obtienen por el cálculo pueden ser, en los casos de luces moderadas, excesivamente pequeños. Ya hemos visto que con los espesores del modelo reducido ensayado, de $2,5 \mathrm{~cm}$, se pueden salvar luces superiores a $10 \mathrm{~m}$, y con $5 \mathrm{~cm}$ de espesor, vanos de $25 \mathrm{~m}$. Pero esto, no sería práctico ni económico. Las pequeñas cantidades de material empleado se compensarian con la carestía de la mano de obra, y las piezas cerámicas (de juguete) serían costosas de fabricar y colocar. Por otra parte, con tan reducidos espesores, la protección térmica de la cubierta sería muy pequeña.

Por lo tanto; aconsejamos fijar un espesor mínimo que creemos no debe ser inferior a $8 \mathrm{~cm}$. De este modo las piezas cerámicas tendrán una altura de $6 \mathrm{~cm}$, dejando $2 \mathrm{~cm}$ para espesores del recubrimiento de hormigón. Y esto nos conduce a una singular pero natural consecuencia: la de que con un espesor total de $8 \mathrm{~cm}$

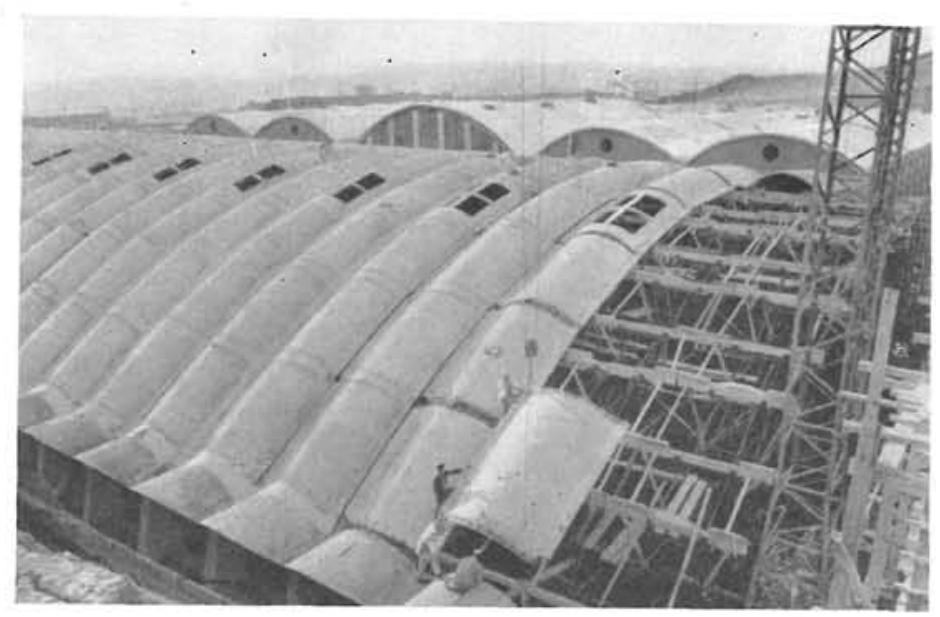

32 
(siendo hueco el $40 \%$ ) y con un mismo peso de $110 \mathrm{~kg}$ por $\mathrm{m}^{2}$, se puede salvar toda una gama de luces hasta icuarenta y cinco metros de luz!, resultado excepcional que permite llegar a soluciones sencillas y bellas en sus dos aspectos-ingenieril y arquitectónico-, como vemos en la gran bóveda de $35 \mathrm{~m}$ de luz y $150 \mathrm{~m}$ de longitud, construída en Madríd para Río-Cerámica -que vamos a reseñar brevemente-y las de Miranda de Ebro, para almacenes de fibra artificial.

\section{Nave de $35 \mathrm{~m}$ de luz de río-cerámica}

Una de las grandes ventajas que pueden obtenerse como consecuencia del reducido peso de estas bóvedas es la de poder suprimir, en muchos casos, los antiestéticos y perturbadores tirantes. Conociendo el peso del metro cuadrado, que es de unos $110 \mathrm{~kg} / \mathrm{m}^{2}$, y contando con otros $100 \mathrm{~kg} / \mathrm{m}^{2}$ para la sobrecarga de viento y nieve, sabemos que para un rebajamiento de $1 / 5$ el empuje por metro lineal de bóveda parabólica de 35 metros de luz es, aproximadamente, $\mathrm{E}=5 / 8 \mathrm{p} 1=$ $=5 / 8=200 \times 35=4.600 \mathrm{~kg}$, que puede ser fácilmente absorbido por contrafuertes. En el caso que estudiamos, al estar distanciados $3 \mathrm{~m}$ se oponen a un empuje de $3 \times 4.600=13.800 \mathrm{~kg}$; y como los arranques de la bóveda pueden situarse a poca altura (por no existir tirantes), las resultantes pueden quedar económicamente centradas en contrafuertes de esbelta sección. La figura 19 nos muestra un interior de la bóveda. El detalle permite distinguir con precisión las piezas cerámicas de las "dovelas-onda", los empalmes y los nervios de rigidez. El espesor de los contrafuertes es solamente de $30 \mathrm{~cm}$ y la bóveda resulta airosamente apoyada, en puntos, sobre ellos. Esta sensación de excepcional ligereza (figs. 19 y 20) es debida a la supresión de las vigas corridas. La solución feliz, de quebrar la onda sobre los contrafuertes y su corte en pico de flauta, ha dado por fruto esta agradable disposición constructiva. Recordemos ahora, que esta solución de viseras ha resultado ser una invariante de la dada al IV Depósito de Aguas de Oviedo hace i¡33 años!!

La elocuencia de las fotografías nos exime de mayores comentarios. Así, por ejemplo, la figura 31 resume todo el dispositivo constructivo montado para la construcción de esta gran nave, en la que se ve el taller de fabricación de las "dovelas-onda", perfectamente alineadas, en espera de la grúa que las eleve y coloque sobre la cimbra tubular, operación que, con más detalle, se aprecia en la figura 32 , en donde una "dovela-onda" va a situarse, para su empalme, a continuación de la anterior.

Dada su gran rigidez (figs. 16 y 18) esta operaciór se realiza fácilmente, pues es suficiente su apoyo sobre cuatro puntos en la cimbra, afinándose su colocación con cuñas.

femos dicho también que este sistema permite la colocación de grandes lucernarios para luz y ventila. ción de la cubierta (fig. 26a).

La gran facilidad constructiva que ofrece el empleo de las "dovelas-onda", que por su gran rigidez pueden fabricarse con la longitud más apropiada a los medios de elevación de que disponga el constructor, permite el empleo de cimbras sencillas tubulares, que son, en definitiva, castilletes enlazados sobre los que se apoyan las "dovelas-onda" (fig. 17), que es el tipo utilizado en esta bóveda para la que se dispusieron elementos de cimbra de $9 \mathrm{~m}$ de longitud, correspondientes a tres vanos zntre contrafuertes. De este modo, sincronizando la fabricación de las "dovelas-onda" y su empleo en la bóveda se lugró, desde un principio, llevar un ritmo de construcción de $9 \mathrm{~m}$ semanales, que fué el ciclo que comprendía: situación de la cimbra, elevación y colocacıón de las "dovelas-onda", rejuntado con fraguado endurecimiento del hormigón, descimbrado y traslado

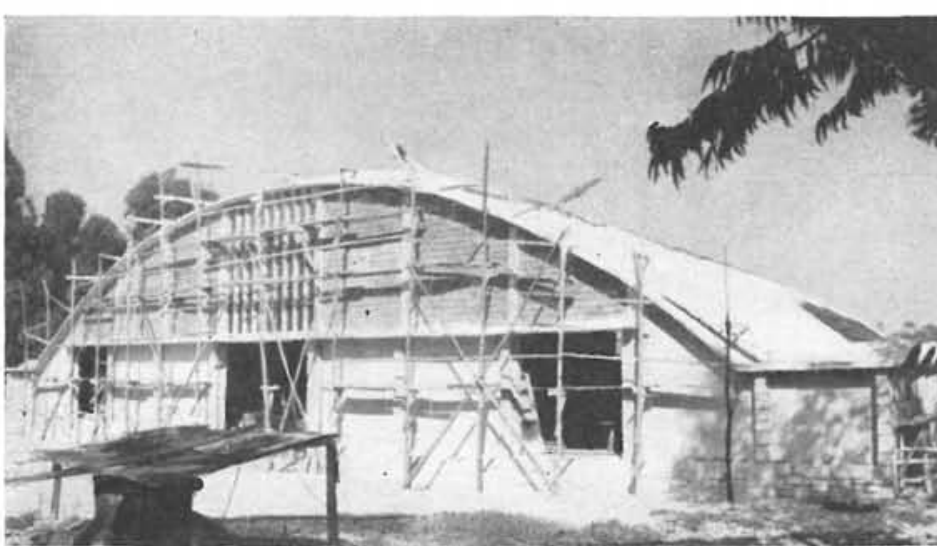

33

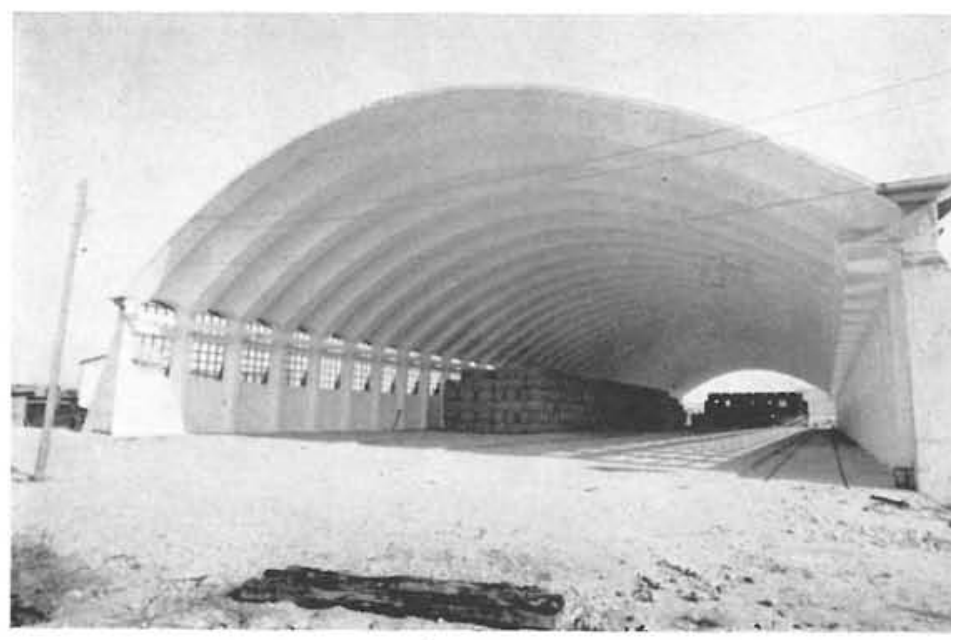

34

35

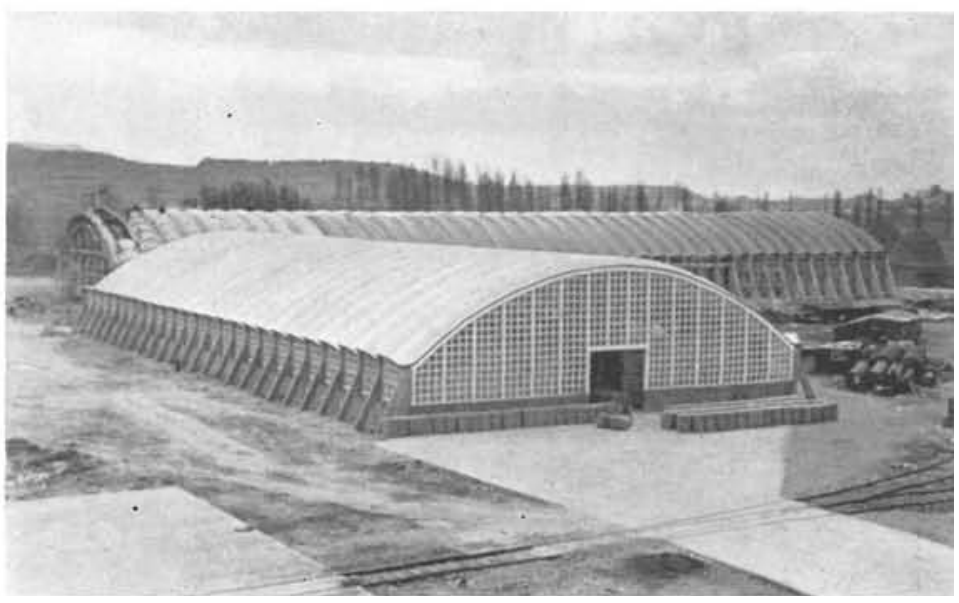



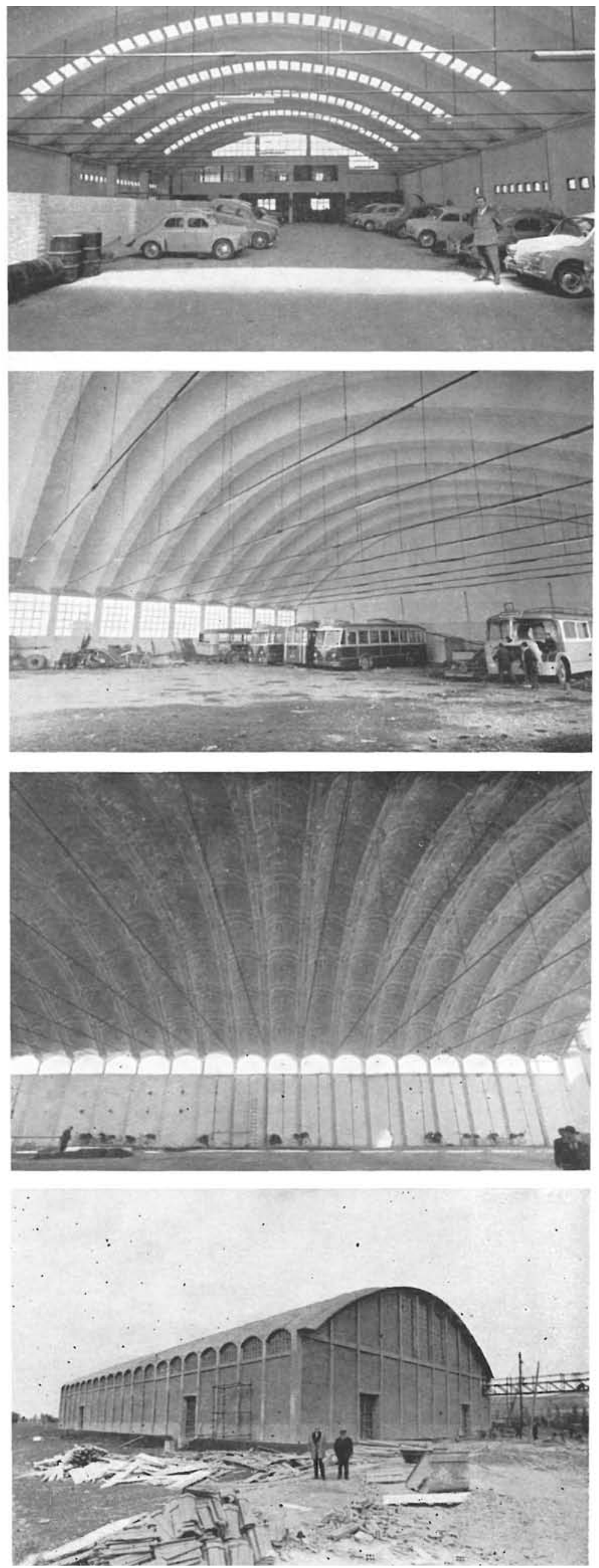

de la cimbra. Total: 7 días. $\mathrm{Y}$ así, sin ningún fallo, se llevó a cabo la ejecución de los $150 \mathrm{~m}$ de la cubierta en menos de 4 meses, confirmando, una vez más, el efecto, en extremo favorable, que ofrecen las piezas cerámicas para el rápido fraguado y endurecimiento del hormigón. Todas las "dovelas-onda" se emplearon en obra a los 5 días de su fabricación, aunque debemos advertir que correspondió a los meses de un verano con elevadas temperaturas.

Ya hemos hecho referencia en este trabajo a nues. tras indecisiones con relación a la colocación de juntas de dilatación en esta bóveda de $150 \mathrm{~m}$ de longitud, pero a sentimiento, comprendimos que no serían necesarias debido a las ondulaciones que facilitarían las deformaciones; como así fué, pues a pesar de que en pleno agosto la superficie de la cubierta soportó temperaturas superiores a $\operatorname{los} 40^{\circ} \mathrm{C}$ con descensos a $20^{\circ} \mathrm{C}$, no se encontraron grietas apreciables, lo que favorece las operaciones de impermeabilización

El cálculo se efectuó partiendo de la sección mecánicamente equivalente a la de la onda, como arco empotrado y comprobando las secciones más desfavorables a sección compuesta. En estas condiciones, el trabajo máximo del hormigón fué de $45 \mathrm{~kg}$ por $\mathrm{cm}^{2}$ y el del acero de $700 \mathrm{~kg}$ por $\mathrm{cm}^{2}$ con un empleo de hierro de $10 \mathrm{~kg}$ por $\mathrm{m}^{2}$ en planta, resultados-que creemos-no igualados en bóvedas comparables.

Como segunda versión de la bóveda descrita debemos mencionar la construída de igual luz, en Portugal, por NOVOPCA, Oporto, y en la que por una prolongación de los contrafuertes se crean unos espacios interiores aprovechables (ng. 33).

Posteriormente, se han construído varias cubiertas onduladas que vamos a describir brevemente, clasificándolas en dos grupos: con contrafuertes y con tirantes.

\section{Bóvedas con contrafuertes}

Son las construídas por F.E.F.A.S.A. en Miranda de Ebro, de $30 \mathrm{~m}$ de luz y longitudes de $75 \mathrm{~m}$ y $120 \mathrm{~m}$ (figura 34). La figura 35 es una vista de conjunto de ambas. Sus "formas", tanto exteriores como interiores, resultan inconfundibles, destacándose por una sencilla y bella armonía, característica del sistema.

Como norma, todas estas bóvedas van apoyadas en puntos materiales sobre los contrafuertes o pilares, con remate en visera más o menos acentuada (solución del IV Depósito de Aguas de Oviedo).

De este modo quedan en libertad las "ondas" de la cubierta para deformarse como un acordeón debido a las variaciones de temperatura. Debido a esto, su comportamiento en este aspecto es perfecto y ninguna bóveda de este tipo lleva juntas de dilatación. Nuestras minuciosas observaciones a este respecto, en particular en los arranques de las bóvedas han confirmado siempre este extremo.

\section{Bóvedas con tirantes}

Vamos a citar algunas más interesantes:

Garaje Renault (Oviedo) (fig. 36). Luz: $22 \mathrm{~m}$. Muestra un ejemplo de solución de lucernarios colocados en el lado de las ondas de orientación más conveniente. El efecto es sumamente agradable. Vista la bóveda del lado opuesto, no se ven. 


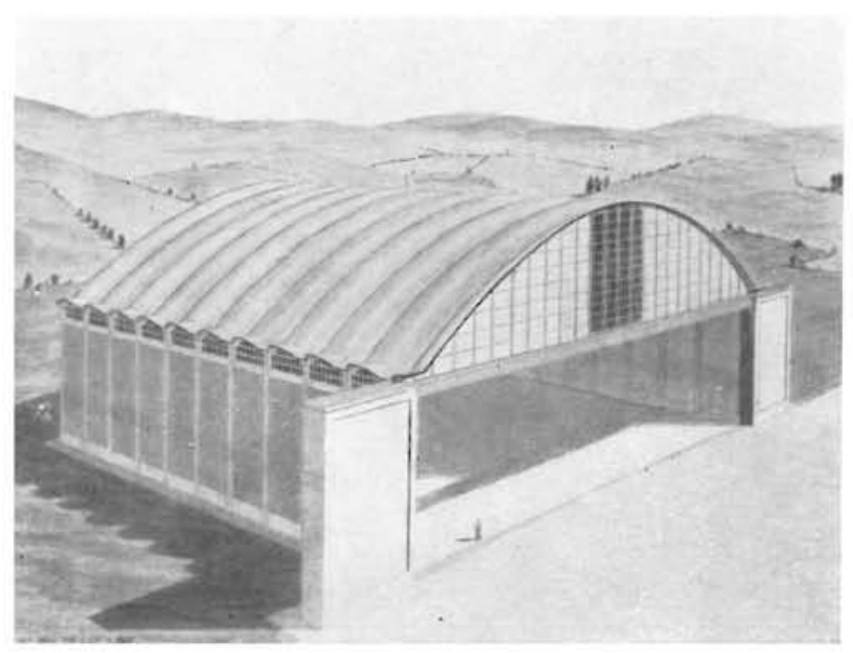

40

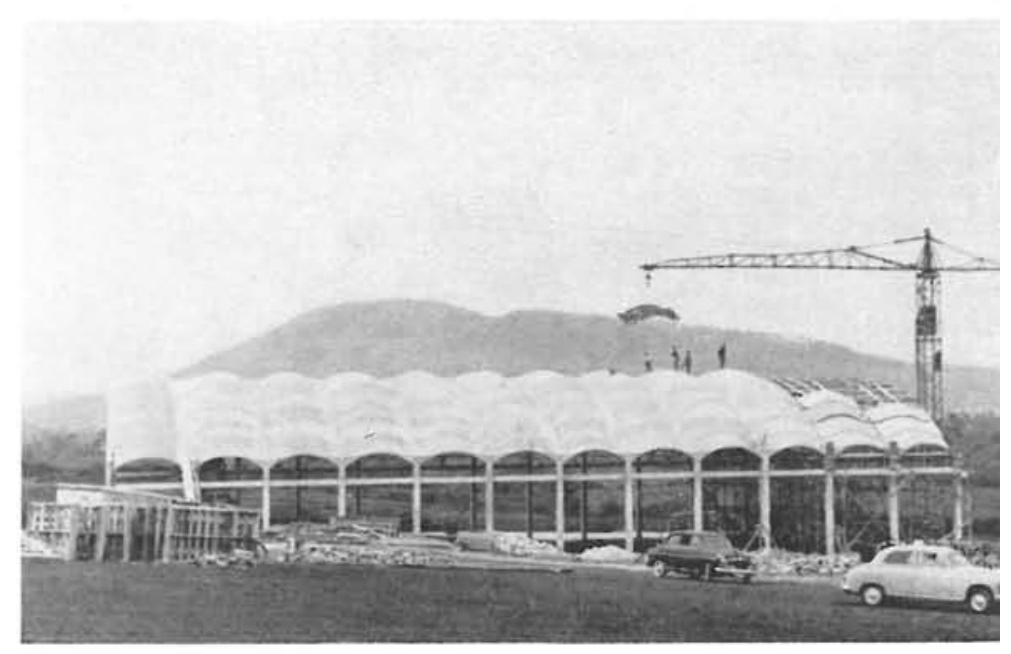

41

Garaje Municipal de Mieres (Asturias) (fig. 37). Luz: $33 \mathrm{~m}$, con una longitud de $40 \mathrm{~m}$. Arranques de la bóveda a $6,50 \mathrm{~m}$ de altura. Tirantes y pilares cada 3 metros.

Almacén de azúcar (Palencia): Bóveda con tirantes (figs. 38 y 39). Luz: 35 m; longitud: 60 m. Separación de pilares y tirantes: $3 \mathrm{~m}$. Altura de tirantes: $7,50 \mathrm{~m}$. El examen de la figura 39 nos muestra su analogía con la proyectada para el hangar de la NATO, en Lisboa, de $60 \mathrm{~m}$ de luz (fig. 40 ).

Como ya hemos dicho, todas estas bóvedas inferiores a $45 \mathrm{~m}$ de luz tienen $8 \mathrm{~cm}$ de espesor (6 +2 ), siendo el ancho de la "dovela-onda" de $3 \mathrm{~m}$; pero la última bóveda ondulada la hemos construído con un ancho de 4 m, que, dado el espesor de $8 \mathrm{~cm}$, es un límite para que los nervios de rigidez no se vean. Con esto se ha conseguido aumentar aún más la esbeltez de la construcción (fig. 41).

Debo hacer constar con gran satisfacción que en estas obras originales, he tenido la colaboración valiosa y entusiasta de técnicos como: Jose María Moreno, Ingeniero Químico y Director de Río-Cerámica, que ha sabido fabricar las difíciles piezas cerámicas que yo necesitaba. De mi compañero José Manuel Fernández Oliva, gran especialista de estructuras Río-Cerámica. De Demetrio Gaspar, doctor en Ciencias Químicas, adjunto a la Dirección de Río-Cerámica y encargado del Laboratorio de Ensayos. Y de Alfonso Gómez, mi más antiguo colaborador, Director de la Cerámica Industrial de San Claudio, de Oviedo.

\section{"Arcos-onda" que pueden sobrepasar los $200 \mathrm{~m}$ de luz}

Pero el atrayente título de este apartado no podría ser una realidad si el sistema de "dovelas-onda" no ofreciese posibilidades dara poder ejecutar grandes bóvedas sobrepasando la luz de $200 \mathrm{~m}$, con soluciones normalmente realizables debido a felices disposiciones constructivas con un empleo mínimo de andamiajes y encofrados, que adquieren extraordinaria importancia en estos casos. Esto es posible merced a la idea perseguida en la concepción de la "dovela-onda", al considerar indispensables los moldes cerámicos para su construcción.

Ya hemos visto que se han construído bóvedas onduladas de $35 \mathrm{~m}$ de luz y que pueden realizarse de $45 \mathrm{~m}$, con un espesor total de $8 \mathrm{~cm}(6+2)$, en las que las "dovelas-onda" se fabrican completas a pie de obra, puesto que su peso aproximado de $110 \mathrm{~km} / \mathrm{m}^{2}$ permite elevarlas fácilmente; siendo otro ejemplo para luces de $60 \mathrm{~m}$ el hangar proyectado por nosotros para Lisboa, con tirantes a $15 \mathrm{~m}$ de altura y espesor de $12 \mathrm{~cm}(10+2)$ (fig. 40 ).

Para luces superiores ofrece el sistema la posibilidad de poder reducir considerablemente el peso elevado, es decir, fabricando la "dovela-onda" con el material indispensable para darla rigidez, para su elevación y colocación sobre la cimbra (no olvidemos que son sólo suficientes 4 puntos de apoyo). Así ha sido concebida la ejecución de la nave de $100 \mathrm{~m}$ de luz, a la que pertenece el modelo ensayado a escala $1 / 10$ (fig. 22), proyectada para una firma alemana.

En ella se aprecia perfectamente todo el dispositivo de ejecución de la bóveda. Las "dovelas-onda" no se construyen totalmente, sino únicamente su estructura resistente. Es decir, los nervios de rigidez, marcos de lucernarios (cuando los tengan) y la parte de relleno de hormigón, entre moldes cerámicos, que envuelve su armadura inferior (fig. 14). Dejando sin hormigonar el resto de "entre-moldes" y todo el recubrimiento de las piezas cerámicas. 


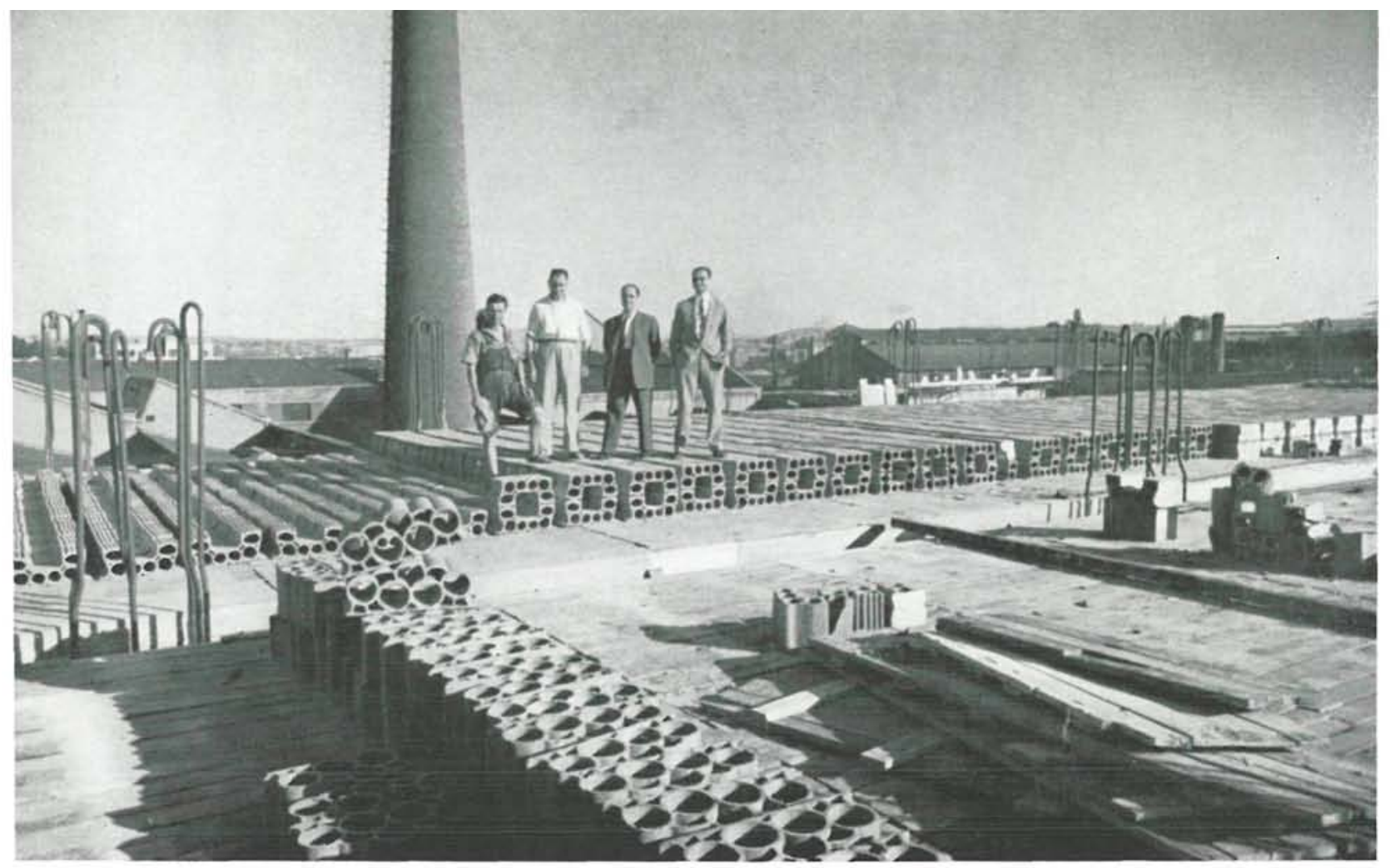

El peso elevado se reduce a la mitad. Una vez colocadas las piezas sobre la cimbra, se realizan los empalmes de las dovelas, completando el hormigonado. Estamos así preparados para poder llevar a cabo bóvedas que pueden pasar de los $100 \mathrm{~m}$ de luz; sin embargo, para mayores realizaciones, del orden de los $200 \mathrm{~m}$ de luz, se puede reducir aún más el peso unitario elevado para poder colocar sobre las cimbras dovelas de $30 \mathrm{~m}^{2}$ de superficie.

La aplicación de los moldes cerámicos nos ofrece, una vez más, la solución correcta y elegante. En efecto: en la amplia gama de fabricación de piezas o moldes cerámicos para la construcción de forjados de pisos existen unas, que hemos proyectado para la construcción de grandes forjados nervados, en las que para facilitar su fabricación se componen de dos piezas, denominadas base y tapa (fig. 42). Se comprende inmediatamente, que si se emplean únicamente "las bases" en la primera fase de la construcción de las "dovelasonda", podemos obtener un "elemento-onda" - llamémosle asi compuesto por los nervios de rigidez y este "forjado-base" que los une y solidariza extraordinariamente ligero. Tan ligero que puede hacer que dicho "elemento-onda" tenga solamente el $25 \%$ del peso de la dovela completa, o sea, unos $160 \mathrm{~kg} / \mathrm{m}^{2} \mathrm{y}$, por lo tanto, siendo su superficie de $3 \times 9=27 \mathrm{~m}^{2}$, el peso que se elevará será, solamente, de $27 \times 160=$ $=4.300$ kilogramos

La figura 43 nos muestra el detalle de un "elemento-onda" así formado, apreciándose claramente los orificios previstos en los nervios de rigidez para el paso de las armaduras, con el fin de reducir a un mínimo el número de empalmes. Una vez colocados, sobre 4 puntos estos "elementos-onda", comienza la segunda fase para la terminación de las dovelas: colocando las tapas cerámicas y procediendo al hormigonado de relleno entre moldes y capa de recubrimiento, previa la colocación de las armaduras.

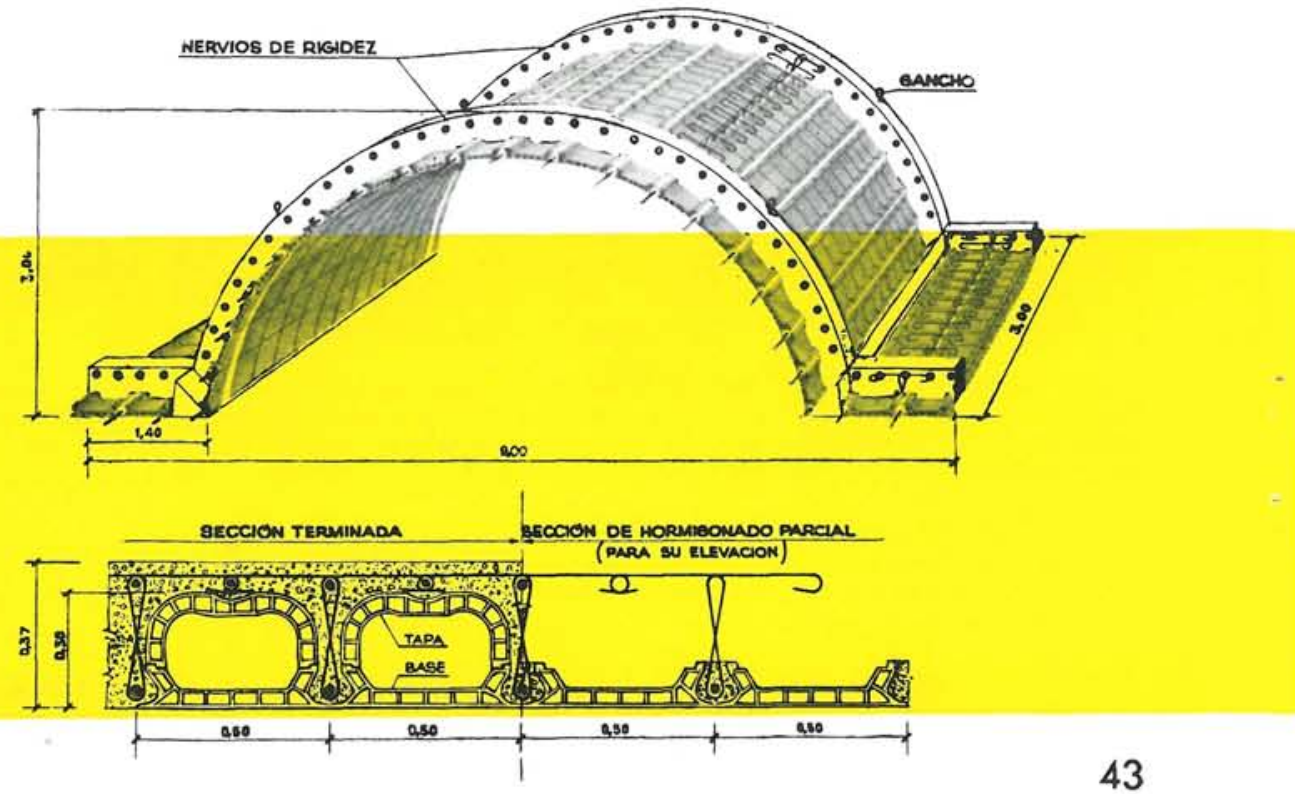




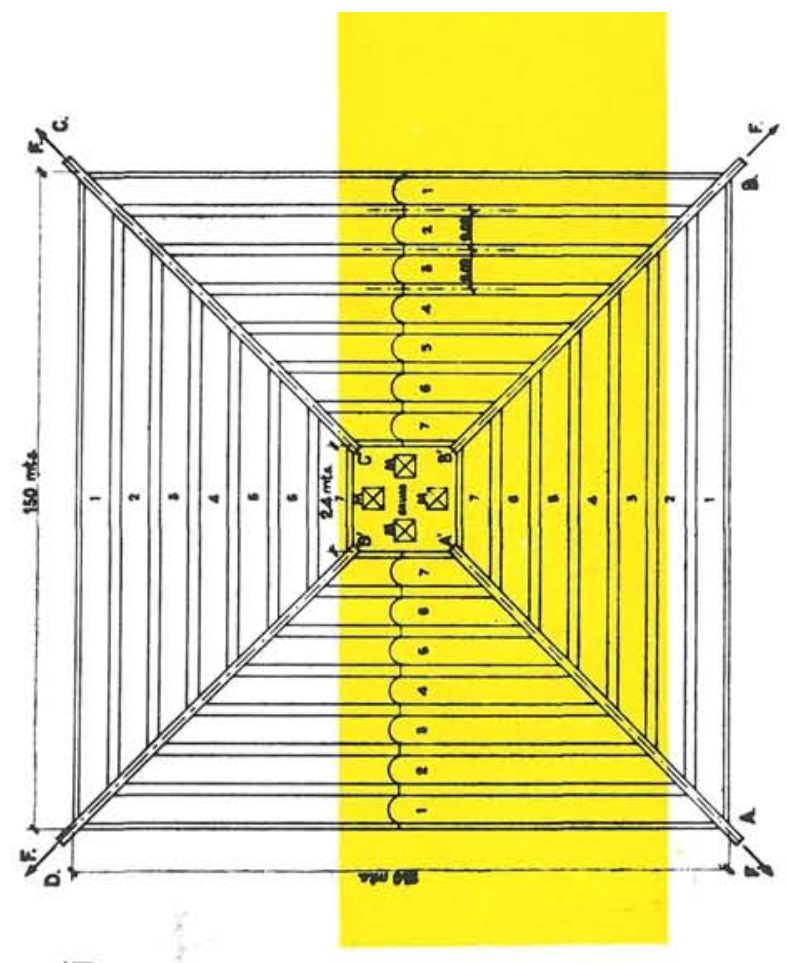

47

\section{Gran rigidez de los "arcos-onda»}

Uno de los problemas que tiene el ingeniero cuando trata de resolver una cubierta "tipo laminar" con estas luces extraordinarias, es el pandeo, bien sea local o conjunto. Es suficiente observar la forma de la estructura de un "arcoonda" integrado por las "dovelas-onda" para comprender que no existe esa posibilidad, dadas las elevadas inercias que, en todos los aspectos, entran en juego.

\section{Aplicaciones}

Desgraciadamente, muy difícil será encontrar aplicaciones para estos "arcos-onda" de $200 \mathrm{~m}$ de luz, porque muy pocas pueden ser las construcciones que requieran una grandiosidad que motive su empleo y que exigen gastos muy elevados. Están indicados en cubiertas para hangares, palacios de deportes, salones de exposiciones, etc., como la realizada en París por Esquillán, con su admirable e impresionante cubierta triangular de $218 \mathrm{~m}$ de lado, que será dudoso, no de superar, sino de igualar. Pero esto no puede cohibirnos el que hagamos constar de que es posible lograr sorprendentes realizaciones con nuestros procedimientos de un modo racional y constructivo, no fácil de conseguir por otros sistemas a base del empleo de materiales comparables.

Y como ejemplo de lo que he expuesto, voy a describir una aplicación de los "arcos-onda" para cubrir una planta cuadrada de $150 \mathrm{~m}$ de lado, apoyada solamente en los cuatro vértices. Es decir, que es una aplicación no forzada de los mismos, que en este caso tendrán un espesor de sólo $30 \mathrm{~cm}(25+5)$ en lugar de $10537 \mathrm{~cm}$ que puede exigir un "arco-onda" de $200 \mathrm{~m}$ de luz. Nuestra planta cuadrada tendría, por lo tanto, una superficie de $22.500 \mathrm{~m}^{2}$, y su esquema estructural está representado en la figura 44 .

No existe en él complicación mecánica ni malabarismo con las fuerzas, como los efectuados en el Mercado de Pola de Siero. Todos los empujes de los "arcos-onda" 1-2-3, etc., tienen unas resultantes $\mathrm{E}$ según los nervios en arco $\mathrm{AA}^{\prime}-\mathrm{BB}^{\prime}-\mathrm{CC}^{\prime}-\mathrm{DD}$ ' que las cimentaciones en A-B-C y D se encargarán de absorber.

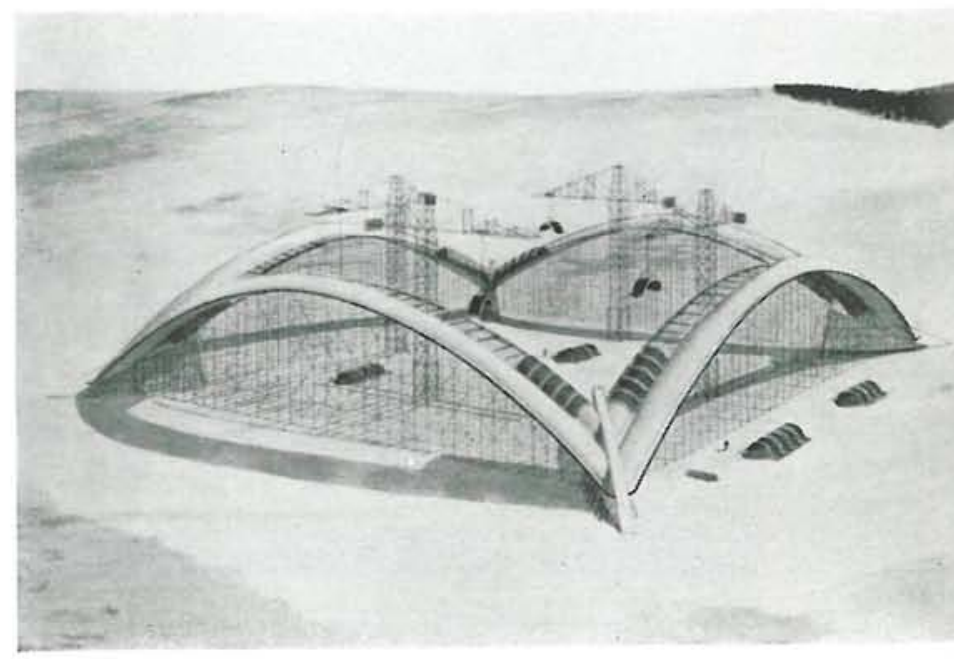

44

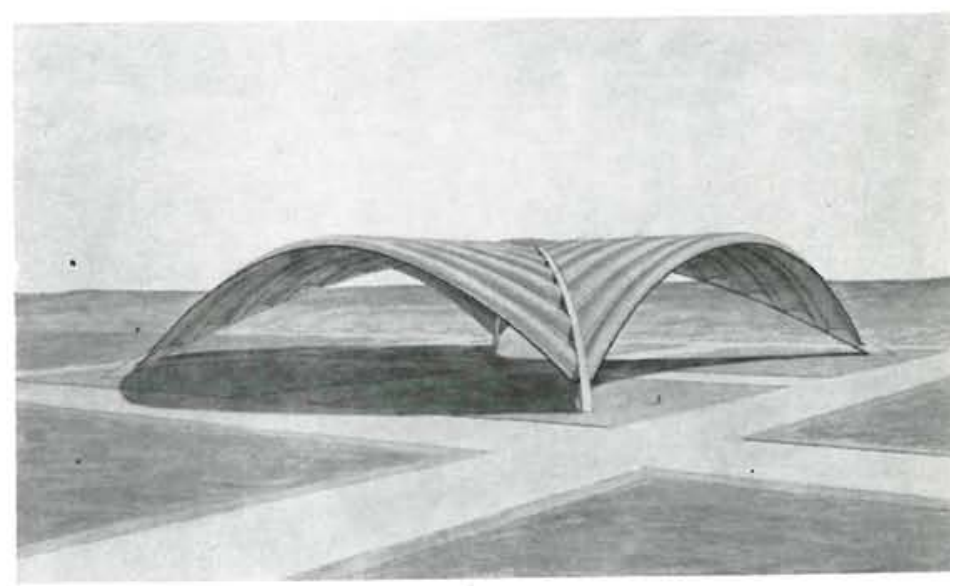

45

46

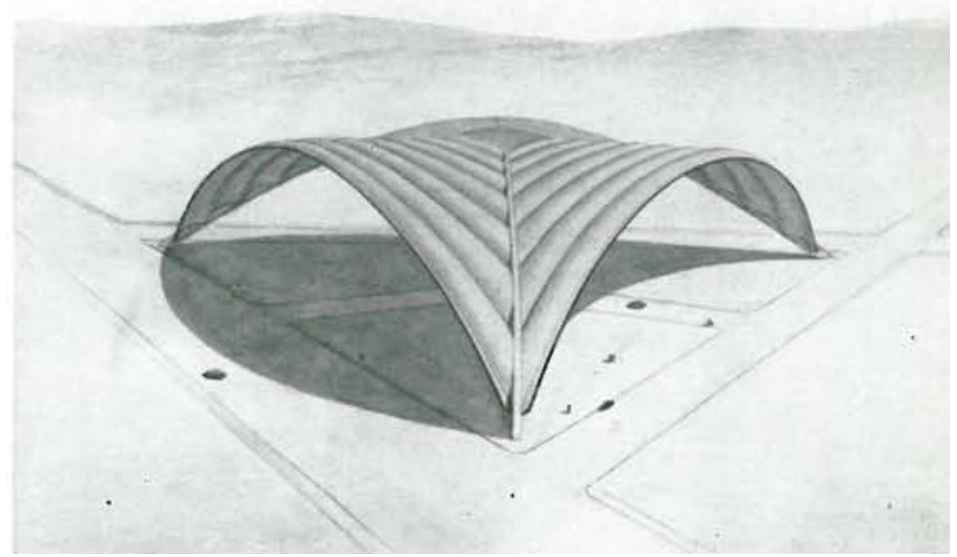


La construcción de la cubierta es muy sencilla, disponiendo de los medios necesarios para ello, pero ninguno de carácter extraordinario. Se precisan 4 grúas que puedan elevar $5.000 \mathrm{~kg}$ de peso a $30 \mathrm{~m}$ de altura con un brazo de $10 \mathrm{~m}$. Se procederá así:

Se comenzará la ejecución simultánea de los 4 "arcos-onda" núm. 1 y los nervios de empalme correspondientes, resultando estable el conjunto construído.

Se correrá la cimbra, procediéndose a la ejecución de los "arcos-onda" núm. 2, con sus trozos de arco de empalme; y asi sucesivamente...

Como los "arcos-onda" van disminuyendo de luz, se puede, en los últimos, disminuir su flecha y su masa, manteniendo su ancho para el mejor aprovechamiento de la cimbra.

En la zona central queda un cuadrado de $24 \mathrm{~m}$ de lado, que permitirá el desmontaje de las 4 grúas, que se cubrirá posteriormente con una estructura metálica, o de elementos de hormigón pretensados, para alojar un magnífico lucernario.

El desagüe de la cubierta se realizará, normalmente, por las vaguadas que crean los "arcos-onda" y por tuberías alojadas dentro de los "arcos-nervios", dado que sus dimensiones lo permiten.

Este sistema constructivo puede aplicarse a cualquier planta poligonal regular, con apoyos en sus vértices.

La figura 44 es un ejemplo del dispositivo constructivo para la planta cuadrada. La figura 45 nos muestra la perspectiva de la obra terminada, y en la figura 46 vemos otra perspectiva correspondiente a una planta triangular de 200 metros de lado.

Esto que he expuesto parece algo de fantasía, porque tal cosa parece la realización de una cubierta capaz de cobijar al Estadio Bernabéu de Madrid con sus 125.000 espectadores, pero sinceramente puedo afirmaros, como ingeniero que siente su obra, que no lo es, por cuanto es el resultado de razonamientos lógicos que creo dictados por el buen sentido y respaldados por la experiencia constructiva de los años que integran casi una vida. Aquí, en estos ejemplos impresionantes, no existe más fantasía que la de encontrar el dinero para realizarlos... Suerte que tuvo Esquillán para realizar en París, ayudado de su genio constructivo, la cubierta más sorprendente de todos los tiempos; porque técnicamente, como habéis visto, no existe problema y como siempre se deberá, en definitiva, al haber encontrado esas "formas" estructurales que son la base del acierto de una construcción.

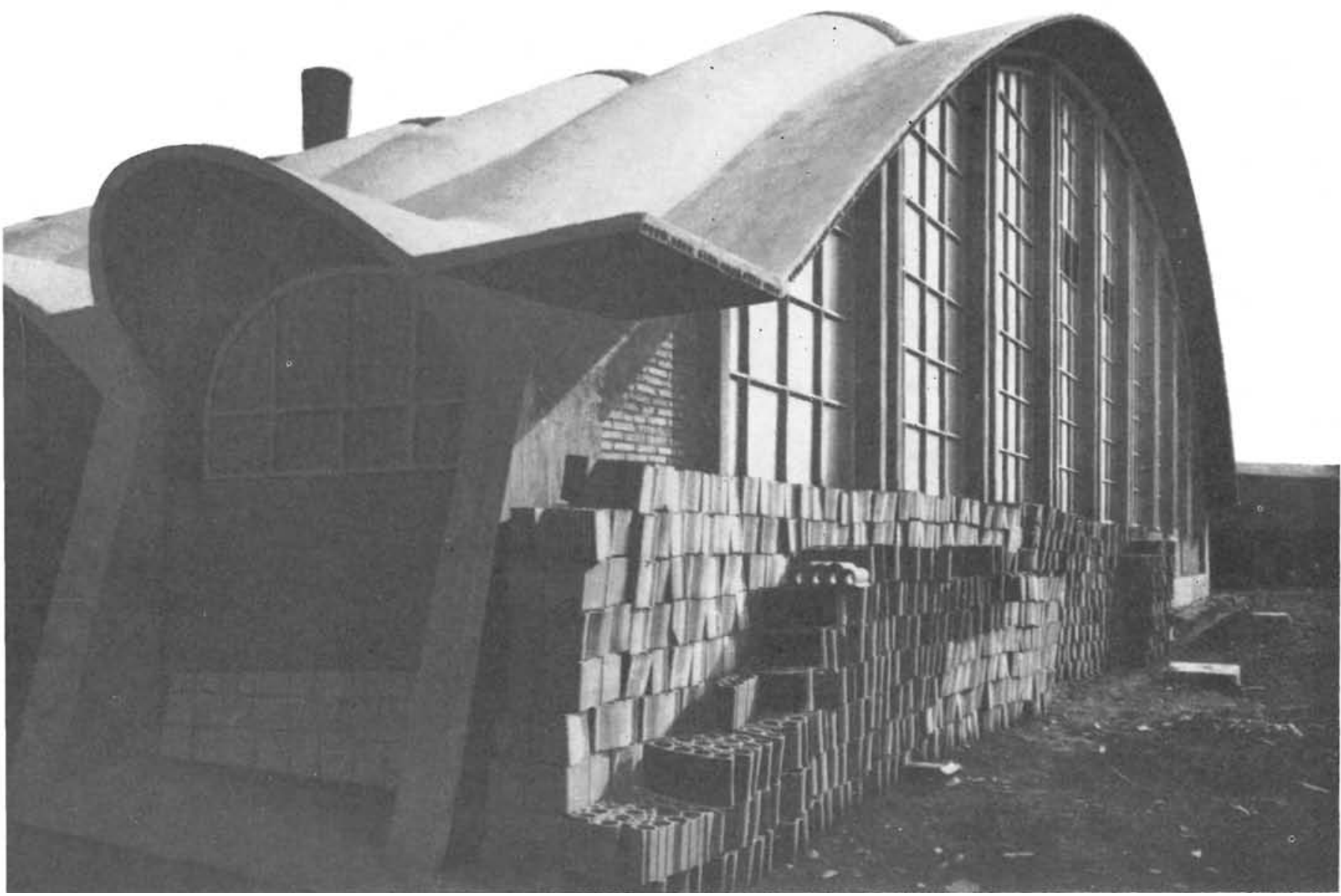

